A Preliminary Survey of Pharmaceuticals and Endocrine Disrupting Compounds in

Treated Municipal Wastewaters and Receiving Rivers of Alberta 
Digitized by the Internet Archive in 2016 


\title{
A Preliminary Survey of Pharmaceuticals and Endocrine Disrupting Compounds in Treated Municipal Wastewaters and Receiving Rivers of Alberta
}

Prepared by:

\author{
Al Sosiak, M.Sc., P.Biol. \\ Water Quality Specialist \\ Environmental Management \\ Southern Region \\ Thorsten Hebben, M.Sc., P.Biol. \\ Limnologist/Water Quality Specialist \\ Monitoring and Evaluation Branch \\ Environmental Assurance
}

September 2005 
Pub. No: $T / 773$

ISBN: $0-7785-3935-0$ (Printed Edition)

ISBN: 0-7785-3937-4 (On-Line Edition)

Web Site: http://www3.gov.ab.ca/env/info/infocentre/publist.cfm

Any comments, questions, or suggestions regarding the content of this document may be directed to:

Environmental Monitoring and Evaluation Branch

Alberta Environment

10th Floor, Oxbridge Place

9820 - 106th Street

Edmonton, Alberta T5K 2J6

Phone: (780) 427-6278

Fax: (780) 422-6712

Additional copies of this document may be obtained by contacting:

Information Centre

Alberta Environment

Main Floor, Oxbridge Place

$9820-106^{\text {th }}$ Street

Edmonton, Alberta T5K 2J6

Phone: (780) 427-2700

Fax: (780) 422-4086

Email: env.infocent@gov.ab.ca 


\section{EXECUTIVE SUMMARY}

Pharmaceuticals, hormones, and other known or suspected endocrine disrupting compounds (EDCs) have been widely detected in various waters throughout the world. Prior to this study, however, sampling for these substances was rather limited within Alberta. In 2002 and 2003, due to concerns about potential impacts on humans, livestock, aquatic organisms, and wildlife, Alberta Environment collected wastewater treatment plant (WWTP) effluents and receiving river water from numerous locations throughout the Province and analysed them for a broad range of organic wastewater contaminants (OWCs). This initial survey, encompassing an assortment of pharmaceuticals, antibiotics, steroids, surfactants, and plasticizers, was designed to determine which compounds are released by WWTPs in Alberta and to assess their presence in receiving river waters.

Results of this study indicate that many of the 105 compounds and isomer mixtures that were tested for occur with some regularity in Alberta WWTP effluents and can be detected in the associated receiving rivers. In the majority of cases, concentrations of target analytes in receiving waters at well-mixed downstream sites were either below detection or several orders of magnitude lower than the same compounds in corresponding WWTP effluents. Certain groups of pharmaceuticals, namely the quinolone and tetracycline antibiotics, were virtually absent in surface waters, while others, including acidic pharmaceuticals, neutral pharmaceuticals, and sulfonamide antibiotics, were markedly lower in rivers than they were in effluents. Similarly, those EDCs that occurred at measurable concentrations in effluents were typically much reduced or below detection in downstream river water. All of the phthalate esters, one of nine monophthalate esters, and all nonylphenol ethoxylates analysed were found in effluents and, albeit at greatly reduced levels, in receiving waters.

At present, surface water guidelines have not yet been established for the vast majority of compounds examined during this study. Nonetheless, the Canadian Council of Ministers of the Environment nonylphenol guideline for the protection of aquatic life $(1.0 \mu \mathrm{g} / \mathrm{L})$ was exceeded by $0.4 \mu \mathrm{g} / \mathrm{L}$ in the Oldman River. However, since toxic equivalents for each river were calculated based on data from a single sample collected at a single point in time, they should be viewed with caution. A need for additional monitoring of OWCs in Alberta's surface waters is indicated. 


\section{TABLE OF CONTENTS}

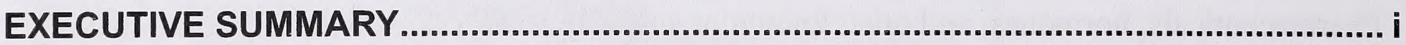

LIST OF TABLES …....................................................................................................... ii

LIST OF FIGURES ............................................................................................................ v

LIST OF APPENDICES ......................................................................................... vi

ACKNOWLEDGEMENTS .......................................................................................... vii

$1.0 \quad$ INTRODUCTION ...................................................................................... 1

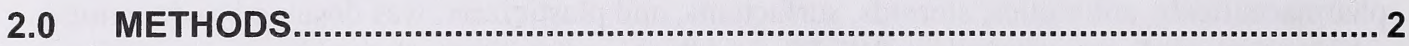

2.1 Analyte Selection ....................................................................................................2

2.2 Site Selection and Sample Collection ....................................................................2

2.3 Sample Extraction.........................................................................................3

2.4 Sample Analyses ..................................................................................................

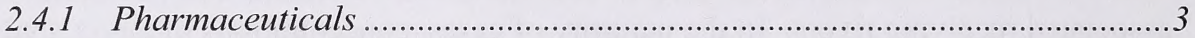

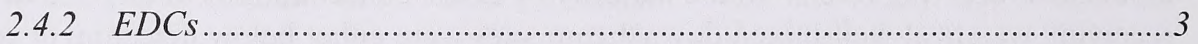

2.5 Quality Assurance ...................................................................................4

3.0 RESULTS AND DISCUSSION ................................................................... 5

3.1 Quality Assurance .............................................................................................5

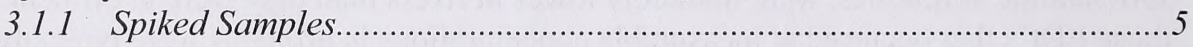

3.1.2 Laboratory Blanks ........................................................................ 5

3.2 Pharmaceuticals .....................................................................................................5

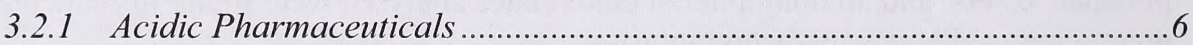

3.2.2 Neutral Pharmaceuticals .................................................................. 6

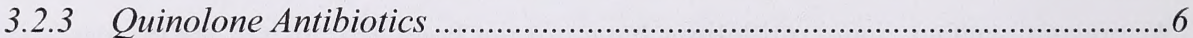

3.2.4 Sulfonamide Antibiotics ................................................................. 7

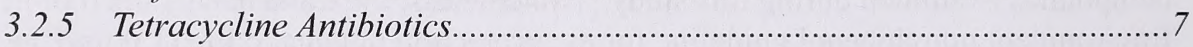

3.3 Endocrine Disrupting Compounds.................................................................7

3.4 Phthalate Esters ...................................................................................................................8

3.5 Nonylphenol ethoxylates.................................................................................................8

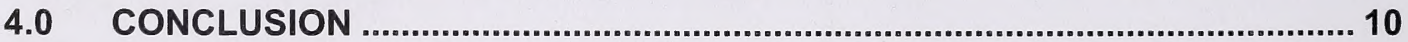

5.0 RECOMMENDATIONS ................................................................ 11

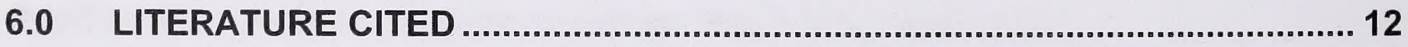

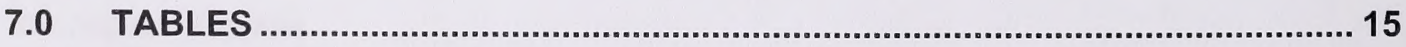

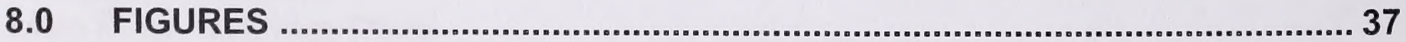

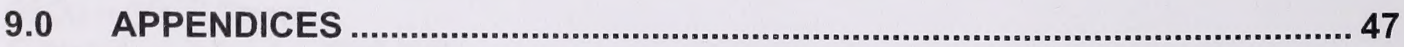




\section{LIST OF TABLES}

Table 1 Summary of acidic pharmaceuticals analysed in WWTP effluents and receiving rivers of Alberta. Details based on Karch (2003).

Table 2 Summary of neutral pharmaceuticals analysed in WWTP effluents and receiving rivers of Alberta. Details based on Karch (2003).

Table 3 Summary of antibiotics analysed in WWTP effluents and receiving rivers of Alberta. Details based on Karch (2003).

Table 4 Summary of endocrine disrupting compounds analysed in WWTP effluents and receiving rivers of Alberta.

Table 5 Summary of phthalate esters, mono-phthalate, and nonylphenol ethoxylates analysed in WWTP effluents and receiving rivers of Alberta. 20

Table 6 Summary of wastewater treatment plants (WWTPs) and river stations sampled....... 21

Table 7 Acidic pharmaceutical concentrations in WWTP effluents and receiving rivers of Alberta $(\mu \mathrm{g} / \mathrm{L})$. Bracketed values indicate standard deviation of triplicate measurements. $\mathrm{ND}=$ Not Detected.

Table 8 Neutral pharmaceutical concentrations in WWTP effluents and receiving rivers of Alberta $(\mu \mathrm{g} / \mathrm{L})$. Bracketed values indicate standard deviation of triplicate measurements. $\mathrm{ND}=$ Not Detected.

Table 9 Quinolone antibiotic concentrations in WWTP effluents and receiving rivers of Alberta $(\mu \mathrm{g} / \mathrm{L})$. Bracketed values indicate standard deviation of triplicate measurements. $\mathrm{ND}=$ Not Detected.

Table 10 Sulfonamide antiobiotic concentrations in WWTP effluents and receiving rivers of Alberta $(\mu \mathrm{g} / \mathrm{L})$. Bracketed values indicate standard deviation of triplicate measurements. $\mathrm{ND}=$ Not Detected.

Table 11 Tetracycline antibiotic concentrations in WWTP effluents and receiving rivers of Alberta $(\mu \mathrm{g} / \mathrm{L})$. Bracketed values indicate standard deviation of triplicate measurements. $\mathrm{ND}=$ Not Detected.

Table 12 EDC concentrations in WWTP effluents of Alberta (ng/L). Steroid estrogens are indicated in italics. ND $=$ Not Detected.

Table 13 EDC concentrations in receiving rivers of Alberta (ng/L). Steroid estrogens are indicated in italics. ND $=$ Not Detected.

Table 14 Phthalate ester concentrations in WWTP effluents of Alberta (ng/L). ND = Not Detected.

Table 15 Phthalate ester concentrations in receiving rivers of Alberta $(\mathrm{ng} / \mathrm{L}) . \mathrm{ND}=\mathrm{Not}$ Detected.

Table 16 Mono-phthalate ester concentrations in WWTP effluents and receiving rivers of Alberta (ng/L). ND = Not Detected; NA = Not Analysed. 
Table 17 Nonylphenol ethoxylate concentrations in WWTP effluents of Alberta (ng/L). $\mathrm{ND}=$ Not Detected.

Table 18 Nonylphenol ethoxylate concentrations in receiving rivers of Alberta (ng/L). ND $=$ Not Detected. 


\section{LIST OF FIGURES}

Figure 1 Pharmaceutical concentrations in WWTP effluents of Alberta. .......................... 38

Figure 2 Pharmaceutical concentrations in receiving rivers of Alberta. ............................... 39

Figure 3 EDC concentrations in WWTP effluents of Alberta (recovery corrected data)......... 40

Figure 4 EDC concentrations in receiving rivers of Alberta (recovery corrected data)........... 41

Figure 5 Phthalate ester concentrations in WWTP effluents of Alberta (recovery corrected data). Note scale differences on y-axes........................................................... 42

Figure 6 Phthalate ester concentrations in receiving rivers of Alberta (recovery corrected data).

Figure 7 Nonylphenol ethoxylate concentrations in WWTP effluents of Alberta (recovery corrected data). Note scale differences on y-axes

Figure 8 Nonylphenol ethoxylate concentrations in receiving rivers of Alberta (recovery corrected data). Note scale difference on y-axes. 


\section{LIST OF APPENDICES}

Appendix I Median recoveries of spiked surrogates from samples of WWTP effluent and receiving river water collected in Alberta......................................................... 48

Appendix II EDC concentrations in blank (type 1, laboratory grade) water samples................ 49

Appendix III Phthalate ester concentrations in blank (type 1, laboratory grade) water

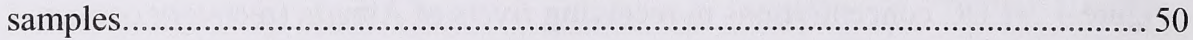

Appendix IV Phthalate monoester concentrations in blank (type 1, laboratory grade) water samples.

Appendix V Nonylphenol ethoxylate concentrations in blank (type 1, laboratory grade) water samples. 


\section{ACKNOWLEDGEMENTS}

We gratefully acknowledge the invaluable contribution of technical and professional staff of Alberta Environment (AENV) to both the sampling program and final report preparation.

Special thanks go to Bridgette Halbig of the Environmental Monitoring and Evaluation Branch (AENV), who provided considerable technical expertise toward data compilation, graphics preparation, and report formatting. Financial support for this study was supplied by the Water Research Users Group of AENV, while some components of the project were funded by the Cities of Calgary (Bonnybrook Wastewater Treatment Plant effluent) and Medicine Hat (Medicine Hat Wastewater Treatment Plant effluent, South Saskatchewan River receiving water). We also wish to thank Dr. Chris Metcalfe of Trent University, Peterborough, ON, and Dr. Michael Ikonomou of the Institute of Ocean Sciences, Department of Fisheries and Oceans, Sidney, BC, for providing their advice and expertise over the course of this study. 


\section{$1.0 \quad$ INTRODUCTION}

During the past ten to fifteen years, the presence of pharmaceuticals, hormones, and other endocrine disrupting compounds (EDCs) in wastewater treatment plant (WWTP) effluents, receiving waters, drinking water, and groundwater has become an issue of increasing international attention and concern (e.g. Sacher et al. 1998, McDowell and Metcalfe 2001, Kolpin et al. 2002, Metcalfe et al. 2002, Boyd et al. 2003, Drewes et al. 2003, Metcalfe et al. 2003a, 2004, Tauxe-Wuersch et al. 2005). Collectively referred to as organic wastewater contaminants (OWCs), it is probable that these compounds have been entering surface- and groundwater systems for as long as people have been using them. Since the detection of clofibric acid, a synthetic blood lipid regulating drug, in river and tap water of Berlin, Germany (Stan et al. 1994), work on the topic has rapidly expanded to include a variety of waters throughout the world. Subsequent research, including a monumental inventory of organic wastewater contaminants (OWCs) in United States rivers (Kolpin et al. 2002), has revealed a broad range of compounds that can be detected regularly in surface waters of industrialized nations, including Canada (Metcalfe et al. 2002). These detections, albeit largely at trace levels, are of concern due to potential impacts on humans, aquatic organisms, livestock, and wildlife.

Although OWCs in the aquatic environment may have numerous origins, it has been shown that municipal WWTPs are a major point source (Drewes et al. 2003). Despite removing a large proportion of pharmaceuticals and EDCs through various treatment processes (Boyd et al. 2003), WWTPs do not eliminate all compounds completely. Consequently, these contaminants tend to be discharged into receiving waters (Heberer 2002). Studies have shown that photodegradation (light-mediated breakdown) and biodegradation (microorganism-mediated breakdown) in the environment contribute to the reduction of OWC concentrations in surface waters (Andreozzi et al. 2003). However, the potential impacts of compounds that resist degradation, as well as breakdown products (metabolites) of more labile (degradable) contaminants, must be considered. Furthermore, even relatively labile substances are given persistent qualities simply through their constant reintroduction into surface waters (Daughton and Ternes 1999).

It is widely recognized that a general lack of monitoring data for many OWCs in surface waters makes accurate risk assessment extremely challenging (Jones 2001). Prior to 2002, however, work on the topic of pharmaceuticals and EDCs in the environment was rather limited within the Province of Alberta. Aside from two studies on WWTP effluents from Calgary (Metcalfe et al. 2003a, Simieritsch et al. 2004), there were no assessments of these contaminants in either effluents or surface waters of the Province. Hence, it was deemed necessary to conduct a preliminary survey of pharmaceuticals, hormones, endocrine disruptors, and other OWCs in WWTP effluents and receiving waters throughout Alberta. As a result, during 2002 and 2003, Alberta Environment (AENV) sampled treated WWTP effluent from the cities of Calgary, Edmonton, Red Deer, Lethbridge, and Medicine Hat for a broad range of OWCs. Receiving waters from the Bow, North Saskatchewan, Red Deer, Oldman, and South Saskatchewan Rivers were analysed for these same compounds. The primary intent of this initial investigation was to determine which substances are released by WWTPs in the Province and to identify the range of compounds that can be detected in receiving waters at fully mixed downstream sites. 


\section{$2.0 \quad$ METHODS}

\subsection{Analyte Selection}

Pharmaceutical compounds chosen for analysis (Tables 1-3) were largely selected from a list of OWCs detected with the highest frequency and at the greatest concentrations in a fairly recent and comprehensive survey of 139 receiving streams throughout the United States (Kolpin et al. 2002). Additional selection criteria for pharmaceuticals were developed by the analytical laboratory (Water Quality Centre, Trent University, Peterborough, Ontario) and included: (1) a review of the drugs most commonly found in WWTP effluents and surface waters in Europe; (2) a review of the prescription patterns for drugs used in clinical applications in Canada; (3) the availability of analytical methods; and (4) the instrumentation and capability of the analytical laboratory itself. Although numerous pharmaceuticals associated exclusively with the livestock industry are also of potential concern, it was assumed that these are less likely to enter surface waters during winter, when most sampling occurred. Hence, they were not incorporated into our study.

The list of target EDCs (Table 4) and other OWCs (Table 5) was originally developed by the analytical laboratory (Institute of Ocean Sciences, Federal Department of Fisheries and Oceans, Sidney, British Columbia) based primarily on an examination of all the compounds that can potentially occur in sewage and pulp mill effluents. Selection criteria for these substances included: (1) the importance of a compound, in terms of potential aquatic and human impacts; (2) the likelihood of a compound passing through a conventional WWTP; and (3) the availability of data from comparable studies.

\subsection{Site Selection and Sample Collection}

Sampling sites (Table 6) were chosen to incorporate WWTPs and associated receiving rivers near areas of greatest human population in Alberta. In all but one instance, a sample of WWTP effluent and one of well-mixed downstream river water were collected. In the case of the South Saskatchewan River, river water was collected upstream of the WWTP at the request and expense of the City of Medicine Hat. Due to prohibitive costs, it was not feasible to sample upstream of the other WWTPs, nor was it possible to analyse WWTP influent. Although replication of individual samples would have resulted in statistically defensible data, it was decided that, in the interests of providing a more comprehensive geospatial picture, limited funds would be best spent on single samples from numerous sites, rather than multiple samples from only a few sites.

During the winter of 2002/2003, Alberta Environment collected grab samples of final treated effluent and river water in pre-cleaned four-litre glass bottles. Each of these bottles was subjected to a single rinse with sample water before being filled. Upon expert consultation (Dr. C. Metcalfe, Trent University), it was agreed that this pre-rinse would saturate any available binding sites on the glass, thereby preventing possible adsorption of some of the target analytes to the sampling bottles. Within 24 hours of collection, samples were sent to Envirotest Laboratories Ltd. (ETL) in Edmonton, Alberta for extraction and subsequent distribution to the appropriate analytical laboratories. All samples were stored in the dark at $4^{\circ} \mathrm{C}$ prior to 
extraction. Since some extracts (Fish Creek WWTP effluent, Bow River water, and Red Deer River water) were lost in transit, it was necessary to resample these sites during low flows in the summer of 2003.

\subsection{Sample Extraction}

Due to the large volumes of water required to achieve low detection limits during analyses, it was considered impractical to ship raw water samples to the analytical laboratories. Therefore, samples were first submitted to ETL (Edmonton, Alberta) for solid phase extraction of pharmaceutical compounds, as well as dichloromethane extraction and stir bar sorptive extraction of EDCs and other OWCs. These procedures were performed in accordance with protocols provided by the analytical laboratories.

\subsection{Sample Analyses}

\subsubsection{Pharmaceuticals}

The Water Quality Centre at Trent University (Peterborough, Ontario) concentrated samples and performed triplicate analyses for pharmaceutical compounds using liquid chromatography/electrospray-tandem mass spectrometry. Method detection limits (MDL; the minimum concentration of a given compound that a particular analytical method can reliably detect in a sample) varied from 1-15 $\mathrm{ng} / \mathrm{L}$ for neutral pharmaceuticals and antibiotics and from 1$25 \mathrm{ng} / \mathrm{L}$ for acidic pharmaceuticals.

\subsubsection{EDCs}

The Institute of Ocean Sciences (Department of Fisheries and Oceans, Sidney, British Columbia) tested samples for a broad range of OWCs, including hormones, contraceptives, plasticizers, surfactants, and other proven or suspected EDCs. Individual di-phthalate esters were analysed using a low-resolution gas chromatography mass spectrometer system (Trace GC/Voyager MS from Thermo Finnigan). Both mono-phthalate esters and isomer mixtures of di-phthalate esters were examined using a liquid chromatograph mass spectrometer system (HPLC system Beckman Model 126/ESI VG Quattro MS, Micromass), while nonylphenol, nonylphenol ethoxylates, and their associated surrogates were analysed via liquid chromatography/electrospray ionization mass spectrometry. Sterols and other EDCs were measured with a high-resolution mass spectrometer.

Method detection limits for variables analysed by the Department of Fisheries and Oceans (DFO) differed markedly among compounds and among samples, depending on the sample matrix (river water vs. effluent). EDCs and steroid estrogens in river water had MDLs from 0.018-371 ng/L, while the same analytes had MDLs from 0.019-689 ng/L in WWTP effluent. Similarly, MDLs for phthalate esters $(0.01-5.7 \mathrm{ng} / \mathrm{L}$ in river water, $0.03-22.2 \mathrm{ng} / \mathrm{L}$ in effluent), mono-phthalate esters $(0.6-4.9 \mathrm{ng} / \mathrm{L}$ in river water, $1.6-11.9 \mathrm{ng} / \mathrm{L}$ in effluent $)$, and nonylphenol ethoxylates (1.78-202 $\mathrm{ng} / \mathrm{L}$ in river water, 4.98-642 $\mathrm{ng} / \mathrm{L}$ in effluent) varied considerably, both among analytes and among individual samples. 
In keeping with the methods of Metcalfe et al. (2003b) and Miao et al. (2004), ETL extracted samples and fortified ("spiked") the extracts with internal drug standards provided by Trent University. By including a known concentration of a particular compound, the Trent laboratory was able to construct a calibration curve, which permits the analyst to compensate for so-called "matrix effects". Compounds that co-occur with target analytes in complex matrices (in this case, WWTP effluent and river water) have a tendency to suppress or, on occasion, enhance signals reported via liquid chromatography/ electrospray-tandem mass spectrometry. By spiking known concentrations of between three and five target pharmaceuticals, a calibration curve can be derived and used to quantify the actual target analytes (Dr. C. Metcalfe, pers. comm.).

Several laboratory blanks (used to identify potential sources of error in laboratory techniques or analytical procedures) were prepared to evaluate results obtained from the DFO laboratory. Since laboratory blanks are typically based on type 1 laboratory grade de-ionized water, analysis thereof should theoretically not result in any detections. A solvent/glassware blank sample extract was prepared by ETL for analysis by the DFO laboratory. In addition, DFO technicians included procedural blanks that were used to assess sample preparation and analysis as well as to adjust data obtained from actual study samples.

Samples to be analysed for EDCs, phthalate esters, and nonylphenol ethoxylates were also spiked by ETL with various labeled surrogate compounds $\left({ }^{13} \mathrm{C}-\mathrm{NP},{ }^{13} \mathrm{C}-\mathrm{NP} 1 \mathrm{EO},{ }^{13} \mathrm{C}-\mathrm{NP} 2 \mathrm{EO}\right.$, ${ }^{13} \mathrm{C}-\mathrm{NP} 3 \mathrm{EO}$, DnOP-d4, d4-DMP, d4-DBP, and d4-DOP) and a non-labeled surrogate (polyoxyethylene-6-myristyl ether), hereafter referred to as Standard 'A' (StdA), prior to sample extraction. This was done to monitor extraction efficiency, evaluate procedure performance, and permit recovery correction of data from actual effluent and stream samples.

With the exception of the mono-phthalate ester samples, which were not spiked with an internal standard by ETL, target concentrations reported by the DFO laboratory were recovery corrected. Due to considerable losses of labeled surrogates ${ }^{13} \mathrm{C}-\mathrm{NP} 1 \mathrm{EO}$ and ${ }^{13} \mathrm{C}-\mathrm{NP} 2 \mathrm{E} 0$, recovery of the labeled surrogate ${ }^{13} \mathrm{C}-\mathrm{NP} 3 \mathrm{EO}$ was used to correct measured concentrations of nonylphenol ethoxylates NP1EO through NP3EO. Similarly, recovery of StdA was applied to adjust results for nonylphenol ethoxylates NP4EO through NP19EO. Concentrations of nonylphenol and those compounds analysed using the high-resolution mass spectrometer were corrected on the basis of DnOP-d4 recovery, while diphthalate esters were adjusted based on recovery of three d4-labeled surrogates (d4-DMP, d4-DBP, and d4-DOP). 


\subsection{RESULTS AND DISCUSSION}

\subsection{Quality Assurance}

\subsubsection{Spiked Samples}

Median surrogate recovery rates for samples analysed by the DFO laboratory were somewhat variable (Appendix I). Most notably, the surrogate ${ }^{13} \mathrm{C}-\mathrm{NP} 1 \mathrm{EO}$ was not detected in any samples, while recoveries of ${ }^{13} \mathrm{C}$-Nonylphenol and ${ }^{13} \mathrm{C}$-NP2EO were low. To account for this, ${ }^{13} \mathrm{C}-\mathrm{NP} 3 \mathrm{EO}$ was used for recovery correction of NP1EO, NP2EO, and NP3EO. Similarly, recovery of DnOP-d4 was used in place of ${ }^{13} \mathrm{C}$-Nonylphenol for adjustment of nonylphenol results. Median recoveries of DnOP-d4, StdA, and the phthalate ester surrogates (d4-DMP, d4-DBP, and d4DOP), on the other hand, were generally quite reasonable. Reasons for poor recovery rates of the nonylphenol and nonylphenol ethoxylate surrogates are unclear. However, it is speculated that this might have been the result of somewhat lengthy holding times, sample overheating, or excessive vacuuming during solvent concentration. Nevertheless, results were recovery corrected by DFO wherever possible.

\subsubsection{Laboratory Blanks}

Analyses of laboratory blanks returned detections for an assortment of EDCs (Appendix II), phthalate esters (Appendix III), and nonylphenol ethoxylates (Appendix V). Bisphenol A, the EDC most frequently detected in blanks, and the phthalate esters are widely used in the manufacture of plastics, which tend to be prevalent in a laboratory environment. Hence, the likelihood of inadvertent sample contamination is presumably fairly high. Similarly, nonylphenol and its various ethoxylates are used in a broad range of products, including shampoos, cosmetics, paints, and cleaning agents. They also have a variety of industrial applications as surfactants, detergents, wetting agents, de-inkers, defoamers, etc. and are used in plastics manufacturing, metal processing, and so forth. Again, the probability of sample contamination in a laboratory appears to be quite high. To account for sample contamination, concentrations of compounds found in laboratory blanks were subtracted from actual sample data. Mono-phthalate esters (Appendix IV) were not detected in blanks and did not require adjustment of results.

\subsection{Pharmaceuticals}

With a few exceptions, standard deviations of triplicate pharmaceutical analyses were very low (Tables 7-11, in brackets). This suggests a considerable degree of precision in the analytical procedures. As might be expected from previous results reported for the United States and Ontario (Kolpin et al. 2002, Metcalfe et al. 2004), a fairly broad suite of drugs was consistently detected in WWTP effluents. Of these, nine compounds (carbamazepine, trimethoprim, sulfamethoxazole, gemfibrozil, ofloxacin, ciprofloxacin, sulfapyridine, cotinine, and pentoxifylline) were omnipresent in effluents collected throughout the Province. Interestingly, only ciprofloxacin was among the 50 most frequently prescribed medications in Canada during 2003 (IMS Health Canada 2003). Compounds measured in receiving waters downstream of WWTP outflows were either detected at much reduced concentrations, relative to effluents, or 
not all. This is not surprising, considering the effects of dilution, photodegradation, and biodegradation.

\subsubsection{Acidic Pharmaceuticals}

It is important to note that the terms "acidic" and "neutral", as used in this report, refer to the laboratory procedures used to analyse pharmaceutical compounds and, aside from providing a means of grouping the substances into convenient categories, bear little pharmacological relevance.

Of the nine acidic drugs analysed (Table 7, Figures 1,2), only two (clofibric acid and ketoprofen) were not detected at least once in either effluents or river waters. Of the remaining seven, anywhere from four to seven were noted in effluents from the four WWTPs in Edmonton and Calgary. With the exception of diclofenac and naproxen, which were detected in the North Saskatchewan River downstream of Edmonton but not in effluents from either of Edmonton's WWTPs, all of these compounds were measured in markedly reduced concentrations at downstream locations. In the case of smaller municipalities (Lethbridge, Medicine Hat, and Red Deer), only gemfibrozil was detected in effluents and at downstream sites. Interestingly, gemfibrozil was also the only acidic pharmaceutical that appeared in the South Saskatchewan River upstream of the Medicine Hat WWTP outflow. This site, although not affected by Medicine Hat effluent, is downstream of all municipalities on the Bow and Oldman Rivers. Hence, compounds detected at this location may be associated with discharges from upstream communities.

\subsubsection{Neutral Pharmaceuticals}

Six of the eight tested neutral pharmaceuticals (trimethoprim, pentoxifylline, cyclophosphamide, carbamazepine, caffeine, and cotinine) appeared in nearly all WWTP effluents (Table 8, Figure 1). Of the remaining two, fluoxetine was only detected in Capital Region and Goldbar WWTP effluents, while norfluoxetine did not appear at all. Neither of these two compounds was found in surface water samples (Table 8, Figure 2). Pentoxyfylline, detected at fairly low levels in effluents from all seven WWTPs, was found only once in surface waters, appearing in the Bow River at Stier's Ranch on January 15, 2003. Similarly, cyclophosphamide was found at very low concentrations in five of seven WWTP effluents but not in any rivers. Based on its low effluent values, it is not surprising that cyclophosphamide was not detected in surface waters. The remaining four compounds - trimethoprim, carbamazepine, caffeine, and cotinine - were consistently reported for most effluents and rivers.

\subsubsection{Quinolone Antibiotics}

Of the six quinolone antibiotics analysed, only three were detected in WWTP effluents (Table 9, Figure 1). Ciprofloxacin and ofloxacin were found in samples from all treatment plants, while norfloxacin was recorded at a fairly broad range of concentrations in effluents from all but the Lethbridge WWTP. These findings are consistent with those of Lindberg et al. (2005), who reported the same three quinolones from effluents of five WWTPs in Sweden. 
Detections of quinolone antibiotics were rare in Alberta surface waters (Table 9, Figure 2). Ciprofloxacin was found in samples from both the North Saskatchewan and Oldman Rivers, while norfloxacin was found only in the North Saskatchewan. No other quinolones were detected in provincial rivers. This may be a reflection of the relative ease with which some of these compounds are degraded or adsorbed to particulate matter (Nowara et al. 1997, Cardoza et al. 2005).

\subsubsection{Sulfonamide Antibiotics}

All of the five analysed sulfonamide antibiotics, commonly known as 'sulfa drugs', were found in effluents from WWTPs serving Edmonton and Calgary (Table 10, Figure 1). In the case of treatment facilities in smaller municipalities, only sulfapyridine and sulfamethoxazole were detected. These same two compounds were found in the North Saskatchewan, Bow, and Oldman Rivers, downstream of their respective WWTPs (Table 10, Figure 2). The remaining three sulfonamides - sulfacetamide, sulfamethazine, and sulfisoxazole - were not detected in any surface waters. Sulfamethoxazole, the only sulfonamide noted in samples from the South Saskatchewan River upstream of Medicine Hat, also happened to be the only one of seven tested sulfonamides detected in a reconnaissance of 51 agricultural streams in the United States (Scribner et al. 2003). This seems reasonable, given its previously demonstrated persistence in field microcosms (Lam et al. 2004). None of the sulfa drugs were detected in the Red Deer River.

\subsubsection{Tetracycline Antibiotics}

Tetracycline antibiotics were rarely detected in WWTP effluents (Table 11, Figure 1). Tetracycline itself was only found twice, appearing in samples collected at the Gold Bar (Edmonton) WWTP and Lethbridge WWTP. The latter sample also contained doxycycline. No other tetracyclines were reported from any of the effluents, nor were any of these antibiotics detected in river water samples (Table 11, Figure 2).

\subsection{Endocrine Disrupting Compounds}

Thirteen of 32 EDCs were consistently detected in WWTP effluents (Table 12, Figure 3). Most of these thirteen compounds, the majority of which were plant or animal sterols, occurred at low concentrations, with very few exceeding $1 \mu \mathrm{g} / \mathrm{L}$. Only nonylphenol, cholesterol, and fucosterol were found in concentrations greater than $1 \mu \mathrm{g} / \mathrm{L}$ in effluents from a few of the treatment plants.

Thirteen EDCs consistently appeared at measurable concentrations in most rivers (Table 13, Figure 4). Not surprisingly, twelve of these were among the thirteen detected most frequently in effluents. As expected, the vast majority of EDC detections in river water were much lower in concentration than those in corresponding effluents. An exception to this was bisphenol A, which exceeded $1.5 \mu \mathrm{g} / \mathrm{L}$ in the Oldman River but was considerably lower in Lethbridge WWTP effluent. Interestingly, the thirteenth compound to be regularly reported from river water samples, desmosterol, was detected in effluents from only three WWTPs but occurred at low concentrations in all five rivers. 
Steroid estrogens (Table 12, in italics) were detected infrequently in WWTP effluents, with only one out of twelve compounds appearing in more than half the samples. Estrone occurred at very low concentrations in six of eight effluents, while estriol and 17ß-Estriol were each detected in four effluents. Three additional compounds - (-)-norgestrel, 17 $\alpha$-ethynylestradiol, and 17 $\alpha-$ estradiol - were each detected only once. The remaining 5 steroid estrogens were not found in WWTP effluents. It is noteworthy that 19-norethindrone, a synthetic ovulation inhibitor not detected in effluent samples, was the only steroid estrogen detected in surface waters, appearing at low concentrations in both the North Saskatchewan and Red Deer Rivers (Table 13, Figure 4). In contrast, all the steroid estrogens included in the present survey, with the exception of Bestradiol-3-benzoate, were found in at least some of 139 receiving streams in the United States (Kolpin et al. 2002).

\subsection{Phthalate Esters}

Endocrine disrupting impacts of many phthalate esters are currently unclear. Nonetheless, several of the phthalate esters included in our study have been shown to exert estrogenic influences in various test organisms (Birkett 2003). Due to their widespread use in plastics manufacturing and their almost ubiquitous presence in the environment (Thuren and Woin 1991, McDowell and Metcalfe 2001), some phthalate esters are viewed as problem pollutants.

With the exception of two blank-corrected values that fell below detection limits, all thirteen target phthalate esters were found at measurable concentrations in effluents from all WWTPs (Table 14, Figure 5). Most occurred at values well below $1 \mu \mathrm{g} / \mathrm{L}$. However, the C8-iso-mix and DEHP ranged as high as $5 \mu \mathrm{g} / \mathrm{L}$ in some effluents. The $\mathrm{C} 9$ - and $\mathrm{C} 10$-iso-mixes also exceeded $1 \mu \mathrm{g} / \mathrm{L}$ in Gold Bar WWTP effluent, while DBP was relatively high in Capital Region WWTP effluent.

Although all of the thirteen phthalate esters examined during this project were detected in most of the receiving rivers, they were generally present at very low concentrations. Only two compounds - the C8-iso-mix and DEHP - appeared at values in excess of $1 \mu \mathrm{g} / \mathrm{L}$ in two rivers. In the case of the Red Deer River, where WWTP effluent concentrations of the two phthalate esters in question were relatively high, this is consistent with expectations. However, reasons for elevated levels of C8-iso-mix and DEHP in the Oldman River are unclear, particularly since Lethbridge effluent concentrations of these two analytes were the lowest of any WWTP. Regardless, the Canadian Council of Ministers of the Environment (CCME) DEHP guideline for the protection of aquatic life $(16 \mu \mathrm{g} / \mathrm{L})$ was never approached during our study.

Only one of nine tested mono-phthalate esters was detected in WWTP effluents (Table 16). The M C8-iso-mix appeared at low concentrations in samples from all but the Red Deer WWTP. It was also measured at minute concentrations in all rivers but the Oldman.

\subsection{Nonylphenol ethoxylates}

Of the nineteen nonylphenol ethoxylates (NPEs) studied, five, NP1EO through NP5EO, were consistently detected in all effluents. However, the full suite of nineteen did appear in effluents from the Capital Region, Fish Creek, Lethbridge, and Medicine Hat WWTPs (Table 17, 
Figure 7). In general, those compounds with fewer ethoxylate groups, as identified by the number in the name (e.g. NP3EO has three ethoxylate groups), occurred at the highest concentrations. This is not surprising, since these are also the most persistent of the NPEs (Ahel et al. 1996, Fujita et al. 2000). Although effluents from the Bonnybrook, Red Deer, Gold Bar, and Capital Region (replicate 1) WWTPs appeared to contain a smaller range of compounds, it should be emphasized that NPEs with longer chains of ethoxylate groups typically undergo microbially-mediated degradation to NPEs with 1-3 ethoxylate groups (Ahel et al. 1996). Hence, longer holding times prior to sample analysis may lead to greater concentrations of NPEs with fewer ethoxylate groups and lower concentrations of NPEs with more ethoxylate groups. This may address, for example, why NP1EO was measured at relatively high concentration in Gold Bar WWTP effluent, while NPEs greater than NP5EO were below detection limits. This may also help explain some of the differences between the two Capital Region WWTP effluent samples - the only instance in which replication took place.

After surface water data were corrected for detections in blank samples (Table 18, Figure 8), only the Bow River sample was shown to contain the full suite of nineteen NPEs. Detections in the five remaining river samples ranged from four to twelve compounds per sample, while concentrations of individual NPEs were generally quite low. Following conversion to nonylphenol equivalents and subsequent summation (Table 18), NPE concentrations in the Oldman River $(1.4 \mu \mathrm{g} / \mathrm{L})$ were found to exceed the CCME nonylphenol guideline value for the protection of aquatic life (1.0 $\mu \mathrm{g} / \mathrm{L}$; Canadian Council of Ministers of the Environment 2001). 


\subsection{CONCLUSION}

This preliminary survey has confirmed the presence of a fairly broad range of pharmaceuticals, endocrine disruptors, and other organic wastewater contaminants in wastewater treatment plant effluents and receiving rivers of Alberta. Overall, concentrations of most of the analysed compounds were similar to those reported from other areas in Canada, the United States, and Europe (e.g. Kolpin et al. 2002, Metcalfe et al. 2004, Sacher et al. 1998). It must be emphasized, however, that values reported herein are the result of an initial scoping survey and should not be taken out of context. The primary purpose of this project was to establish the presence or absence of selected OWCs in effluents and surface waters of the Province. Hence, reported data are based largely on non-replicated, one-time samples and should be viewed with caution. It is also important to note that many of the studied OWCs could potentially be subject to fluctuations over time, both on a daily and seasonal basis. In addition, the possibility of longterm and cumulative environmental impacts cannot be ruled out. Therefore, having established that certain contaminants do appear with some degree of regularity throughout the Province, a more thorough, longer-term study that would help assess the risk of OWCs to the aquatic environment is warranted. 


\subsection{RECOMMENDATIONS}

Results of this survey demonstrate that a fairly broad range of pharmaceuticals, endocrine disrupting compounds (EDCs), and other organic wastewater contaminants (OWCs) are released via wastewater treatment plant (WWTP) effluents to receiving waters in Alberta:

1. Long-term monitoring of river water upstream and downstream of major urban centres is recommended as a means of evaluating spatial and temporal trends as well as seasonal variation in OWC concentrations. Such monitoring would also permit a more thorough assessment of compounds of concern, their distribution, frequency of occurrence, and potential implications for water quality and ecosystem health in the Province.

2. Additional work on the fate and transport of pharmaceuticals, EDCs, and other OWCs in provincial surface waters is suggested. Knowledge obtained could subsequently be used to support quantitative modelling for these compounds as well as risk assessments both in terms of water quality and ecosystem health. Studies could include analyses of target OWCs in river sediments and the tissues of various aquatic organisms such as invertebrates and fishes.

3. Analyses of both WWTP influent and WWTP effluent may help evaluate treatment efficiency and could be used to compare between different treatment processes and treatment plants. Knowledge thus obtained may be used in the future to help reduce pharmaceutical, EDC, and other OWC loading to surface waters.

4. Data obtained from the above-recommended studies, in conjunction with those from other sources, should be used in the future to support the development of guidelines for pharmaceuticals, EDCs, and other OWCs in surface waters. 


\subsection{LITERATURE CITED}

Ahel, M., C. Schaffner and W. Giger. 1996. Behaviour of alkylphenol polyethoxylate surfactants in the aquatic environment - III. Occurrence and elimination of their persistent metabolites during infiltration of river water to groundwater. Water Research 30: 3746.

Andreozzi, R., M. Raffaele and P. Nicklas. 2003. Pharmaceuticals in STP effluents and their solar photodegradation in aquatic environments. Chemosphere 50: 1319-1330.

Birkett, J.W. 2003. Scope of the problem. In: Birkett, J.W. and J.N. Lester (eds). Endocrine disrupters in wastewater and sludge treatment processes. Lewis Publishers, Boca Raton, 295 pp.

Boyd, G.R., H. Reemtsma, D.A. Grimm and S. Mitra. 2003. Pharmaceuticals and personal care products (PPCPs) in surface and treated waters of Louisiana, USA and Ontario, Canada. Science of the Total Environment 311: 135-149.

Canadian Council of Ministers of the Environment. 2001. Canadian water quality guidelines for the protection of aquatic life: Nonylphenol and its ethoxylates. In: Canadian environmental quality guidelines, 1999, Canadian Council of Ministers of the Environment, Winnipeg.

Cardoza, L.A., C.W. Knapp, C.K. Larive, J.B. Belden, M. Lydy and D. Graham. 2005. Factors affecting the fate of ciprofloxacin in aquatic field systems. Water, Air, and Soil Pollution 161: 383-398.

Daughton, C.G. and T.A. Ternes. 1999. Pharmaceuticals and personal care products in the environment: agents of subtle change? Environmental Health Perspectives 107: 907938.

Drewes, J.E., T. Heberer, T. Rauch, and K. Reddersen. 2003. Fate of pharmaceuticals during ground water recharge. Ground Water Monitoring and Remediation 23: 64-72.

Fujita, M., M. Ike, K. Mori, H. Kaku, Y. Sakaguchi, M. Asano, H. Maki and T. Nishihara. 2000. Behaviour of nonylphenol ethoxylates in sewage treatment plants in Japan biotransformation and ecotoxicity. Water Science and Technology 42: 23-30.

Heberer, T. 2002. Tracking persistent pharmaceutical residues from municipal sewage to drinking water. Journal of Hydrology 266: 175-189.

IMS HEALTH Canada. Compuscript 2003. http:/www.imshealthcanada.com/htmen/1 $0 \quad 12$.htm

Jones, O.A.H., N. Voulvoulis and J.N. Lester. 2001. Human pharmaceuticals in the aquatic environment: a review. Environmental Technology 22: 1383-1394. 
Karch, A.M. 2003. Lippincott's Nursing Drug Guide. Lippincott, William and Wilkins. A Wolters Kluwer Co., Philadelphia.

Kolpin, D.W., E.T. Furlong, M.T. Meyer, E.M. Thurman, S.D. Zaugg, L.B. Barber and H.T. Buxton. 2002. Pharmaceuticals, hormones, and other organic wastewater contaminants in U.S. streams, 1999-2000: a national reconnaissance. Environmental Science and Technology 36: 1202-1211.

Lam, M.W., C.J. Young, R.A. Brain, D.J. Johnson, M.A. Hanson, C.J. Wilson, S.M. Richards, K.R. Solomon, and S.A. Mabury. 2004. Aquatic persistence of eight pharmaceuticals in a microcosm study. Environmental Toxicology and Chemistry 23: 1431-1440.

Lindberg, R.H., P. Wennberg, M.I. Johansson, M. Tyklind, and B.A.V. Andersson. 2005. Screening of human antibiotic substances and determination of weekly mass flows in five sewage treatment plants in Sweden. Environmental Science and Technology 39: 3421-3429.

McDowell, D.C. and C.D. Metcalfe. 2001. Phthalate esters in sediments near a sewage treatment plant outflow in Hamilton Harbour, Ontario: SFE extraction and environmental distribution. Journal of Great Lakes Research 27: 3-9.

Metcalfe, C.D., B.G. Koenig, D.T. Bennie, M. Servos, T.A. Ternes and R. Hirsch. 2003a. Occurrence of neutral and acidic drugs in the effluents of Canadian sewage treatment plants. Environmental Toxicology and Chemistry 22: 2872-2880.

Metcalfe, C.D., B.G. Koenig, X-S. Miao and J. Struger. 2002. Pharmaceuticals in surface waters in the Lower Great Lakes. International Association for Great Lakes Research, Conference on Great Lakes Research, Winnipeg, June 2-6.

Metcalfe, C.D., X-S. Miao, B.G. Koenig and J. Struger. 2003b. Distribution of acidic and neutral drugs in surface waters near sewage treatment plants in the lower Great Lakes, Canada, Environmental Toxicology and Chemistry 22: 2881-2889.

Metcalfe, C.D., X-S. Miao, W. Hua, R. Letcher and M. Servos. 2004. Pharmaceuticals in the Canadian environment. In: Kümmerer, K. (Ed.), Pharmaceuticals in the Environment: Sources, Fate, Effects and Risks, Second Edition, Springer-Verlag, 6787.

Miao, X-S., F. Bishay, M. Chen and C.D. Metcalfe. 2004. Occurrence of antimicrobials in the final effluents of wastewater treatment plants in Canada. Environmental Toxicology and Chemistry. 38:3533-3541.

Nowara, A., J. Burhenne and M. Spiteller. 1997. Binding of fluoroquinolone carboxylic acid derivatives to clay minerals. Journal of Agricultural and Food Chemistry 45: 14591463. 
Sacher, F., E. Lochow, D. Bethmann and H. Brauch. 1998. Vorkommen von Arzneimittelwirkstoffen in Oberflächenwässern (Occurrence of drugs in surface waters). Vom Wasser 90: 233-243.

Scribner, E.A., W.A. Battaglin, J.E. Dietze, and E.M. Thurman. 2003. Reconnaissance data for glyphosate, other selected herbicides, their degradation products, and antibiotics in 51 streams in nine midwestern states, 2002.

Simieritsch, R., M.C. Ryan, E. Dixon and A. Chu. 2004. Screening of sewage influent and effluent for pharmaceuticals and organic contaminants using GC/MS and LC/MS/MS. Canadian Water and Wastewater Association Conference 2004.

Stan, H-J., T. Heberer and M. Linkerhaegner. 1994. Occurrence of clofibric acid in the aquatic system - Is the use in human medical care the source of the contamination of surface, ground and drinking water? Vom Wasser 83: 57-68.

Tauxe-Wuersch, A., L.F. De Alencastro, D. Grandjean and J. Tarradellas. 2005. Occurrence of several acidic drugs in sewage treatment plants in Switzerland and risk assessment. Water Research 39: 1761-1172.

Thuren, A. and P. Woin. 1991. Effects of phthalate esters on the locomotor activity of the freshwater amphipod Gammarus pulex. Bulletin of Environmental Contamination and Toxicology 46: 159-166. 
7.0 TABLES

A Preliminary Survey of Pharmaceuticals and Endocrine Disrupting Compounds in Treated Municipal Wastewaters and Receiving Rivers of Alberta 


\section{Table 1 Summary of acidic pharmaceuticals analysed in WWTP effluents and receiving rivers of Alberta. Details based on Karch (2003).}

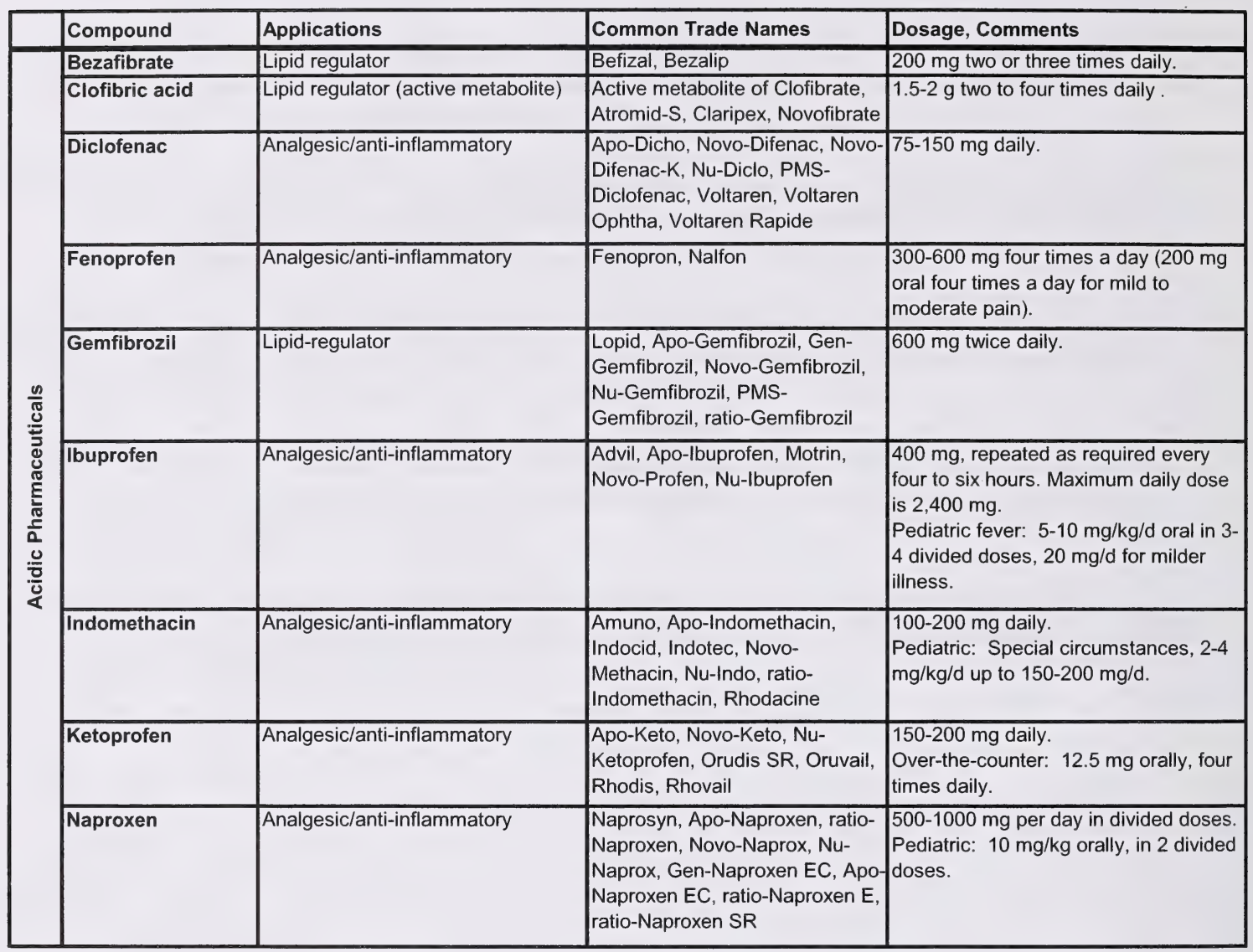


Table 2 Summary of neutral pharmaceuticals analysed in WWTP effluents and receiving rivers of Alberta. Details based on Karch (2003).

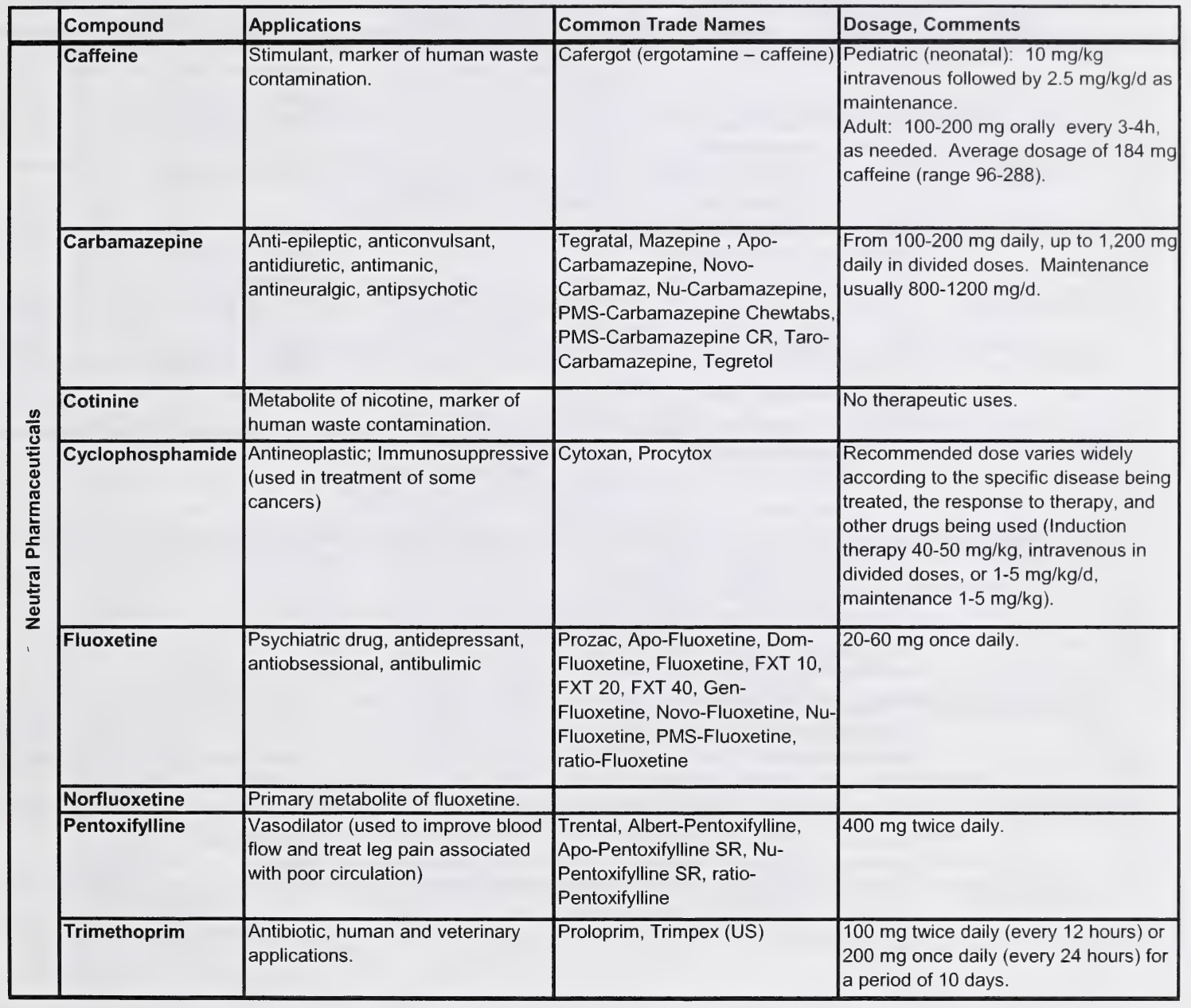




\section{Table 3 Summary of antibiotics analysed in WWTP effluents and receiving rivers of}

Alberta. Details based on Karch (2003).

\begin{tabular}{|c|c|c|c|c|}
\hline & Compound & Applications & Common Trade Names & Dosage, Comments \\
\hline \multirow{5}{*}{ 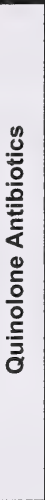 } & Ciprofloxacin & Antibacterial & $\begin{array}{l}\text { Ciflox, Ciproxan, Ciproxin, Cipro, } \\
\text { Ciprobay, Velmonit }\end{array}$ & $\begin{array}{l}1000 \mathrm{mg} \text { daily. Lowest dosage for } \\
\text { urinary tract infections, } 100-250 \mathrm{mg} \\
\text { orally every } 12 \mathrm{hr} \text { for } 3 \text { days. }\end{array}$ \\
\hline & Enrofloxacin & $\begin{array}{l}\text { Only veterinary applications for } \\
\text { different types of infections. }\end{array}$ & Baytril & $5-20 \mathrm{mg} / \mathrm{kg} / \mathrm{day}$. \\
\hline & Norfloxacin & $\begin{array}{l}\text { Use in human medicine: urinary } \\
\text { tract (bladder) infections. }\end{array}$ & $\begin{array}{l}\text { Apo-Norflox, Noroxin, Novo- } \\
\text { Norfloxacin, PMS-Norfloxacin }\end{array}$ & $400 \mathrm{mg}$ twice daily. \\
\hline & Oxolinic acid & $\begin{array}{l}\text { Veterinary medicine for use in fin } \\
\text { fish, calves, pigs and poultry . }\end{array}$ & Utibid & $\begin{array}{l}12 \mathrm{mg} / \mathrm{kg} / \text { day. Pigs and poultry } 20 \\
\mathrm{mg} / \mathrm{kg} / \text { day. }\end{array}$ \\
\hline & Pipemidic acid & $\begin{array}{l}\text { Antimicrobial used for } \\
\text { gastrointestinal, biliary, and urinary } \\
\text { infections. }\end{array}$ & Pipram & $\begin{array}{l}500 \mathrm{mg} \text { twice daily for urinary tract } \\
\text { infections. }\end{array}$ \\
\hline \multirow{2}{*}{ 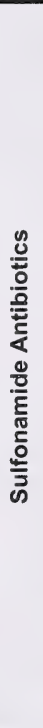 } & Sulfamethazine & $\begin{array}{l}\text { Greatest quantity of all } \\
\text { sulfonamides applied in veterinary } \\
\text { medicine; also used in human } \\
\text { medicine. Used to treat respiratory } \\
\text { diseases and promote accelerated } \\
\text { weight gain in food animals. }\end{array}$ & Sulphamezathine, Sulmet & Used as cream or tablets. \\
\hline & Sulfamethoxazole & $\begin{array}{l}\text { Treatment of infections caused by a } \\
\text { variety of bacteria and protozoa; } \\
\text { often administered in combination } \\
\text { with trimethoprim (TMP/SMX). }\end{array}$ & Gantanol, Urobak & $\begin{array}{l}\text { Adults take } 2 \mathrm{~g} \text { to start, then } 1 \mathrm{~g} \text { every } \\
8-12 \text { hours, depending on the severity } \\
\text { of the infection. The total daily dosage } \\
\text { should not exceed } 3 \mathrm{~g} \text {. }\end{array}$ \\
\hline \multirow{4}{*}{ 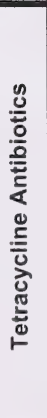 } & Chlorotetracycline & $\begin{array}{l}\text { Mainly used as growth promoter for } \\
\text { chicken, swine, and turkey. }\end{array}$ & Aureomycin, Achromycin & $\begin{array}{l}5.5 \mathrm{mg} / \mathrm{kg}(0.00055 \%) \text { of complete } \\
\text { feed. }\end{array}$ \\
\hline & Doxycycline & $\begin{array}{l}\text { Used to treat lung, urinary tract, } \\
\text { throat, and skin infections. }\end{array}$ & $\begin{array}{l}\text { Nordox, Apo-Doxy, Doxycin, } \\
\text { Novo-Doxylin, Nu-Doxycycline, } \\
\text { ratio-Doxycycline, Vibra-Tabs }\end{array}$ & $\begin{array}{l}200 \mathrm{mg} \text { for the first dose, followed by } \\
100 \mathrm{mg} \text { once daily. }\end{array}$ \\
\hline & Oxytetracycline & $\begin{array}{l}\text { Mainly as growth promoter for } \\
\text { livestock. }\end{array}$ & Terramycin & \\
\hline & Tetracycline & $\begin{array}{l}\text { Used to treat infections of the skin } \\
\text { and Lyme disease. Also used in } \\
\text { combination with other compounds } \\
\text { for treatment of the bacterium } \\
\text { (Helicobacter pylori) that causes } \\
\text { ulcers. }\end{array}$ & $\begin{array}{l}\text { Tetra-Sol, Apo-Tetra, Novo- } \\
\text { Tetra, Nu-Tetra }\end{array}$ & $250-500 \mathrm{mg}$ four times daily. \\
\hline
\end{tabular}




\section{Table 4 Summary of endocrine disrupting compounds analysed in WWTP effluents and receiving rivers of Alberta.}

\begin{tabular}{|c|c|c|}
\hline & Target Analyte & Description and/or Full Name \\
\hline \multirow{32}{*}{ 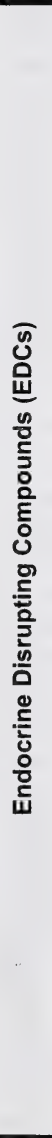 } & Nonylphenol & $\begin{array}{l}\text { Potent EDC from surfactants, formulant in pesticides, lubricating oil additive, } \\
\text { curing of epoxy resins }\end{array}$ \\
\hline & Cholesterol & Animal derived sterol \\
\hline & Fucosterol & Sterol found in seaweed \\
\hline & Stigmasterol & Major wood derived sterol \\
\hline & Campesterol & Major wood derived sterol \\
\hline & B-Sitosterol & Major wood derived sterol \\
\hline & Coprostan-3-one & Fecal neutral sterol \\
\hline & Cholestanol (Coprostanol) & Cholesterol derivative \\
\hline & Stigmastanol & Major wood derived sterol \\
\hline & Bisphenol A & Potent EDC from PVC plastics \\
\hline & 7-Ketocholesterol & Cholesterol oxidation product \\
\hline & Desmosterol & Cholesterol derivative \\
\hline & Kaempferol & Flavonoid found in woody plants \\
\hline & 6-Ketocholestanol & Cholesterol oxidation product \\
\hline & Genistein & Flavonoid found in soy products and pulp mill effluents \\
\hline & Totarol & Antibacterial diterpenoid \\
\hline & Pinosylvin & Stilbene found in Pinus species \\
\hline & a-Zearalanol & Veterinary drug - growth promoter \\
\hline & Naringenin & Flavonoid found in woody plants \\
\hline & Ergosterol & Main sterol produced by fungi \\
\hline & Estrone & Endogenous female estrogen \\
\hline & (-)-Norgestrel & Synthetic ovulation inhibitor (birth control pill) \\
\hline & $17 \alpha-$ Ethynylestradiol & Synthetic ovulation inhibitor (birth control pill) \\
\hline & Estriol & Endogenous female estrogen \\
\hline & 17ß-Estradiol & Endogenous female estrogen \\
\hline & 17a-Estradiol & Endogenous female estrogen \\
\hline & Equilin & Hormone replacement therapy drug \\
\hline & Testosterone & Endogenous male androgen \\
\hline & d-Equilenin & Hormone replacement therapy drug \\
\hline & Mestranol & Synthetic ovulation inhibitor (birth control pill) \\
\hline & 19-Norethindrone & Synthetic ovulation inhibitor (birth control pill) \\
\hline & B-Estradiol-3-benzoate & Veterinary drug - growth promoter \\
\hline
\end{tabular}




\section{Table 5 Summary of phthalate esters, mono-phthalate, and nonylphenol ethoxylates analysed in WWTP effluents and receiving rivers of Alberta.}

\begin{tabular}{|c|c|c|}
\hline & Target Analyte & Description and/or Full Name \\
\hline \multirow{16}{*}{ 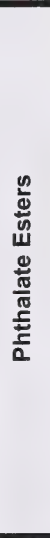 } & Dimethyl phthalate - DMP & Used as a rubber softener and in wood stains and varnishes \\
\hline & Diethyl phthalate - DEP & Used as a plasticizer and in cosmetics, insecticides, and aspirin \\
\hline & Diisobutyl phthalate - DIBP & Solvent, PVC production, synthetic rubber manufacture \\
\hline & Di-n-butyl phthalate - DBP & PVC and nitrocellulose lacquers - carpets, paints, insect repellents, hair spray \\
\hline & Butylbenzyl phthalate - BBP & PVC and nitrocellulose resin. Used to coat electrical wires \\
\hline & Di(2-ethylhexyl) phthalate - DEHP & Very commonly used plasticizer in a broad range of consumer products \\
\hline & Di-n-octyl phthalate - DnOP & Plasticizer, pesticide \\
\hline & Dinonyl phthalate - DNP & Film and sheeting, extrüded and molded automotive applications \\
\hline & C6-iso-mix & \\
\hline & C7-iso-mix & \\
\hline & C8-iso-mix** & DEHP + DnOP and reported from GC/MS analysis of individual DEHP and DnOP \\
\hline & C9-iso-mix & \\
\hline & C10-iso-mix & \\
\hline & d-4 dimethyl phthalate - d-4 DMP & \\
\hline & d-4 di-n-butyl phthalate - d-4 DBP & \\
\hline & d-4 di-n-octyl phthalate - d-4 DOP & \\
\hline \multirow{11}{*}{ 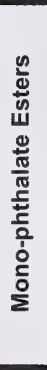 } & Monomethyl phthalate - MMP & Dimethyl phthalate metabolite. \\
\hline & Monoethyl phthalate - MEP & Diethyl phthalate metabolite. \\
\hline & Monobutyl phthalate - MButP & Dibutyl phthalate metabolite. \\
\hline & M C6-iso-mix & \\
\hline & Monobenzyl phthalate - MBzP & Butylbenzyl phthalate metabolite. \\
\hline & M C7-iso-mix & \\
\hline & MEHP+MnOP ( M C8-iso mix) & \\
\hline & M C9-iso-mix & \\
\hline & M-C10-iso-mix & \\
\hline & MBuP - C13 & Mono-n-butyl phthalate-ring-1.2-13C-dicarboxyl-13-C2 \\
\hline & MEHP - C13 & Mono-2-ethylhexyl phthalate-ring-1.2-13C-dicarboxyl-13-C2 \\
\hline \multirow{19}{*}{ 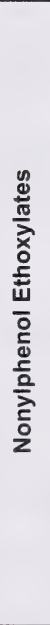 } & NP1EO & \multirow{19}{*}{$\begin{array}{l}\text { These compounds are widely used in household laundry detergents, shampoos, } \\
\text { cosmetics, household cleaners, latex paint, and spermicides; industrial } \\
\text { surfactants, detergents, wetting agents, dispersants, defoamers, de-inkers, and } \\
\text { antistatic agents. }\end{array}$} \\
\hline & NP2EO & \\
\hline & NP3EO & \\
\hline & NP4EO & \\
\hline & NP5EO & \\
\hline & NP6EO & \\
\hline & NP7EO & \\
\hline & NP8EO & \\
\hline & NP9EO & \\
\hline & \begin{tabular}{|l} 
NP10EO \\
\end{tabular} & \\
\hline & NP11EO & \\
\hline & NP12EO & \\
\hline & NP13EO & \\
\hline & NP14EO & \\
\hline & NP15EO & \\
\hline & NP16EO & \\
\hline & NP17EO & \\
\hline & NP18EO & \\
\hline & NP19EO & \\
\hline
\end{tabular}




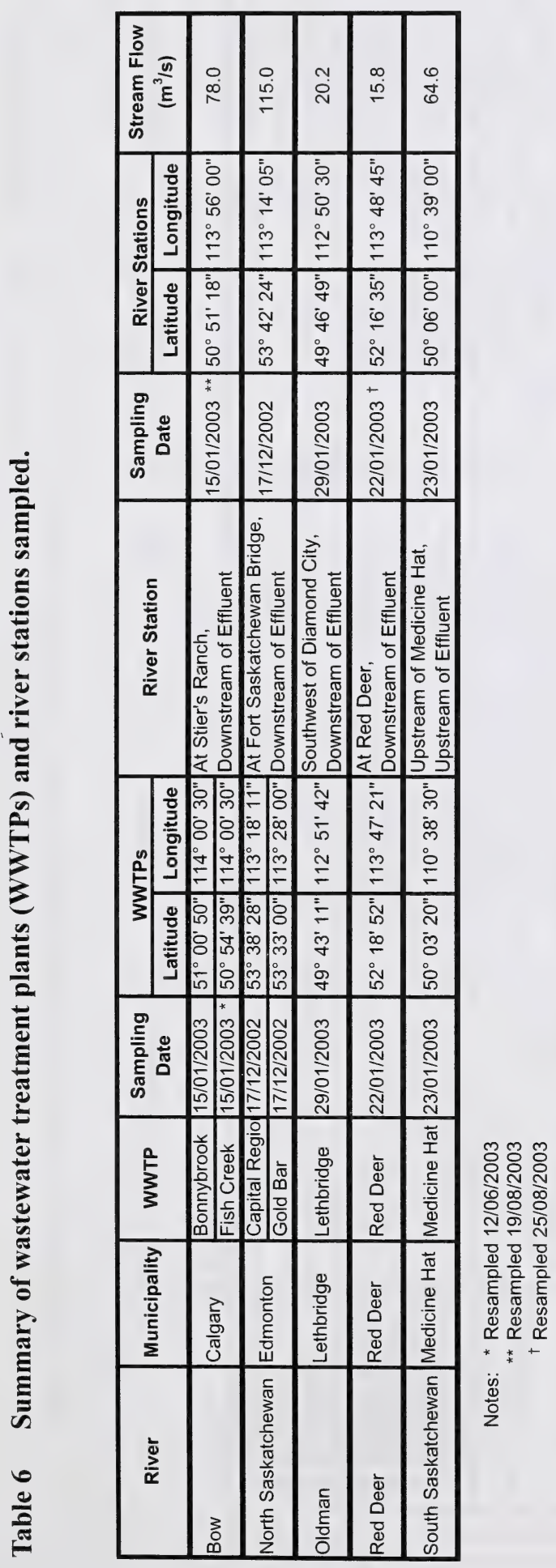




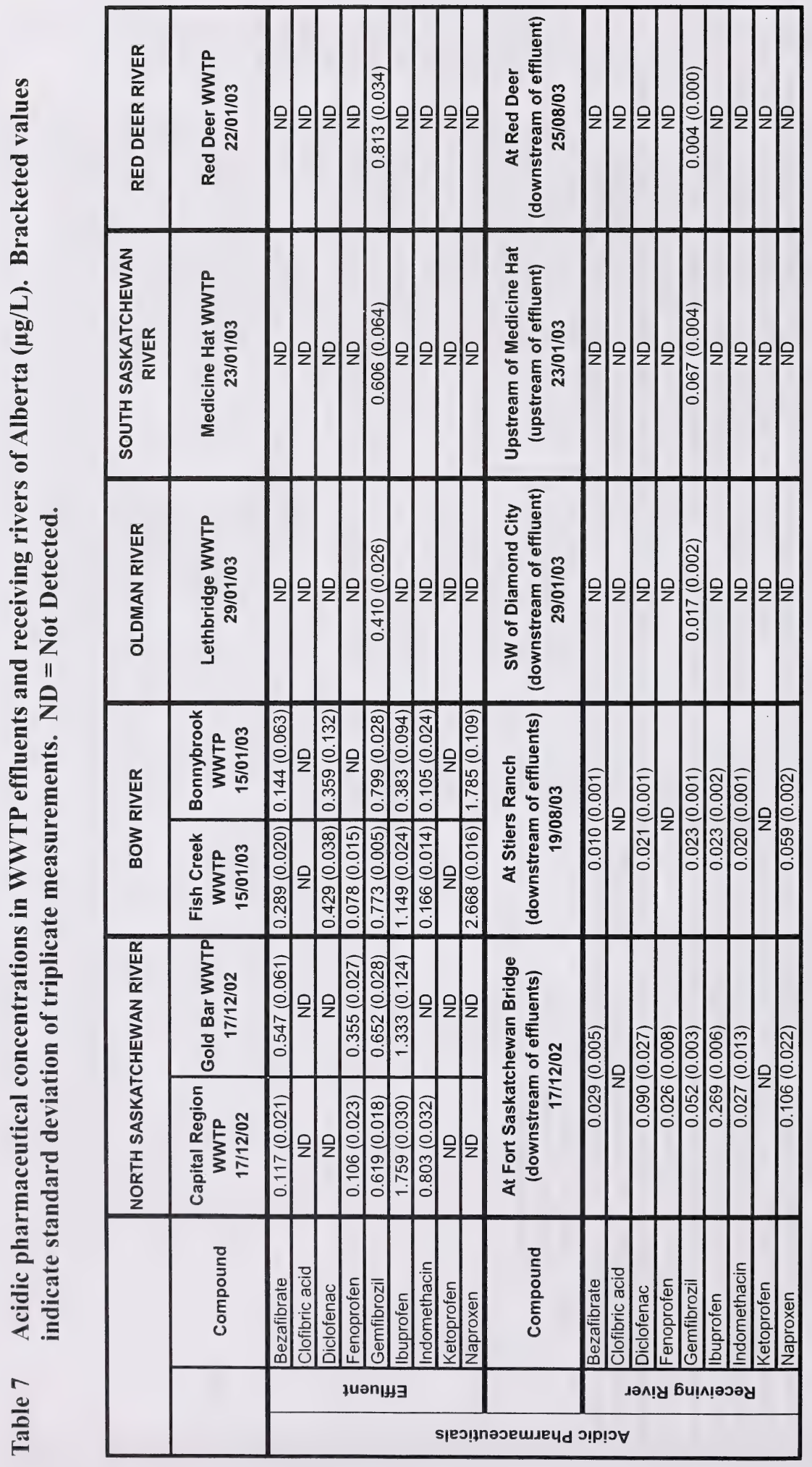




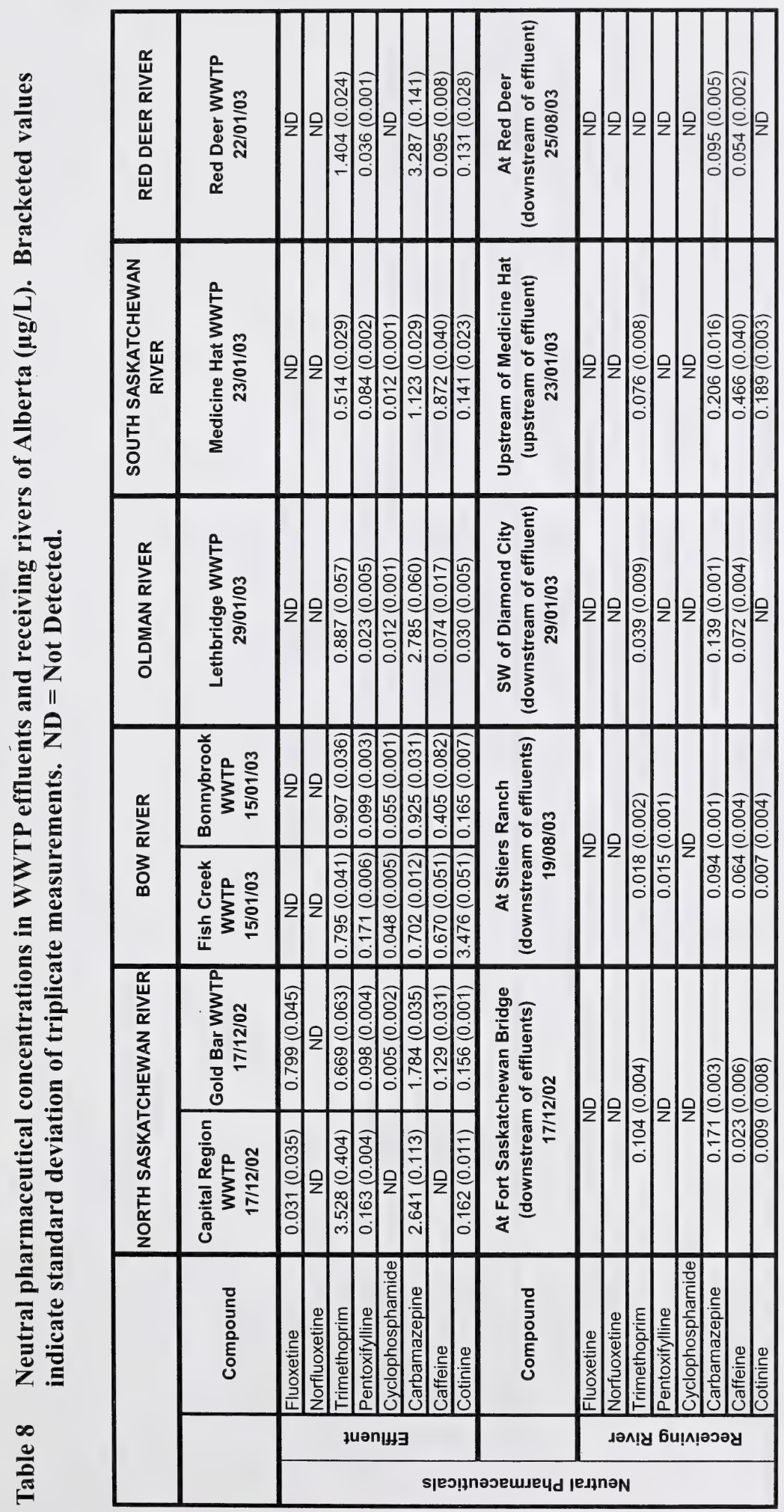




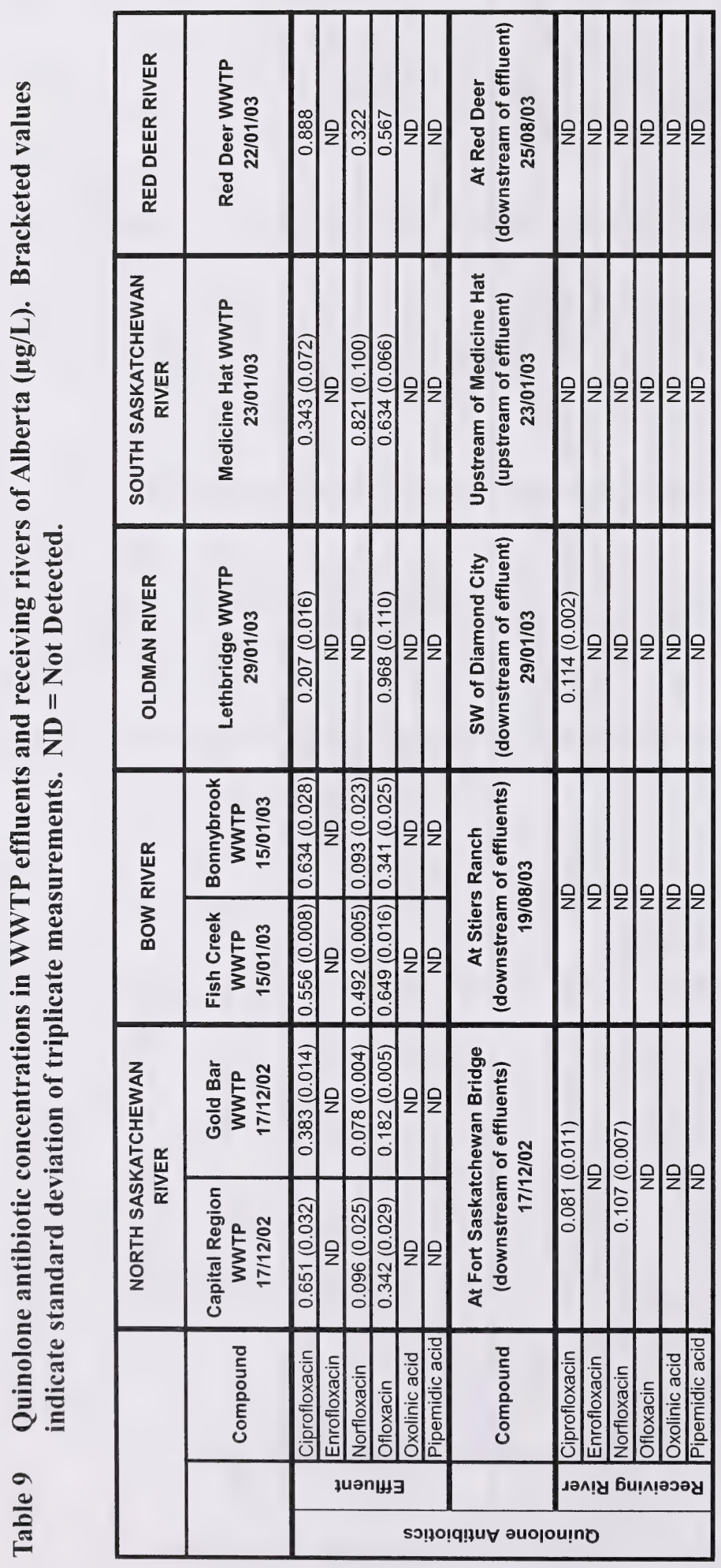




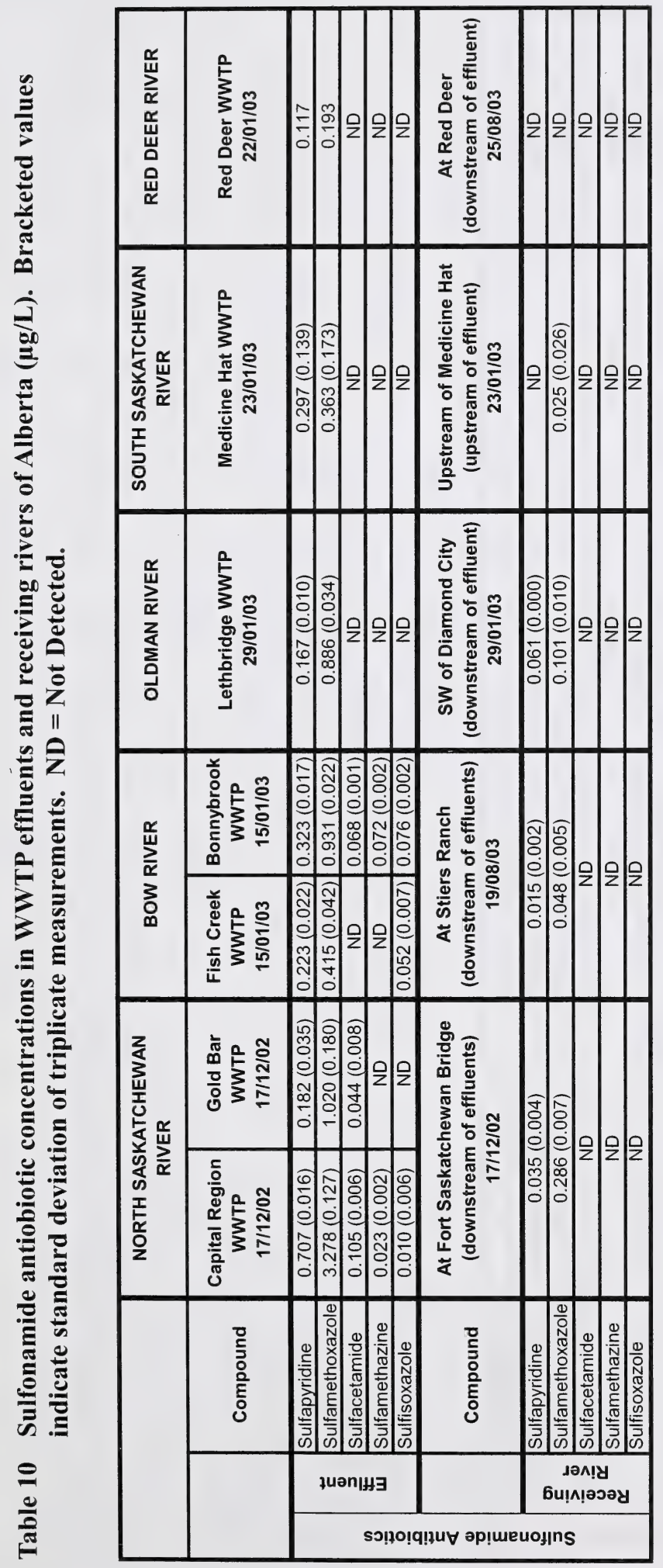




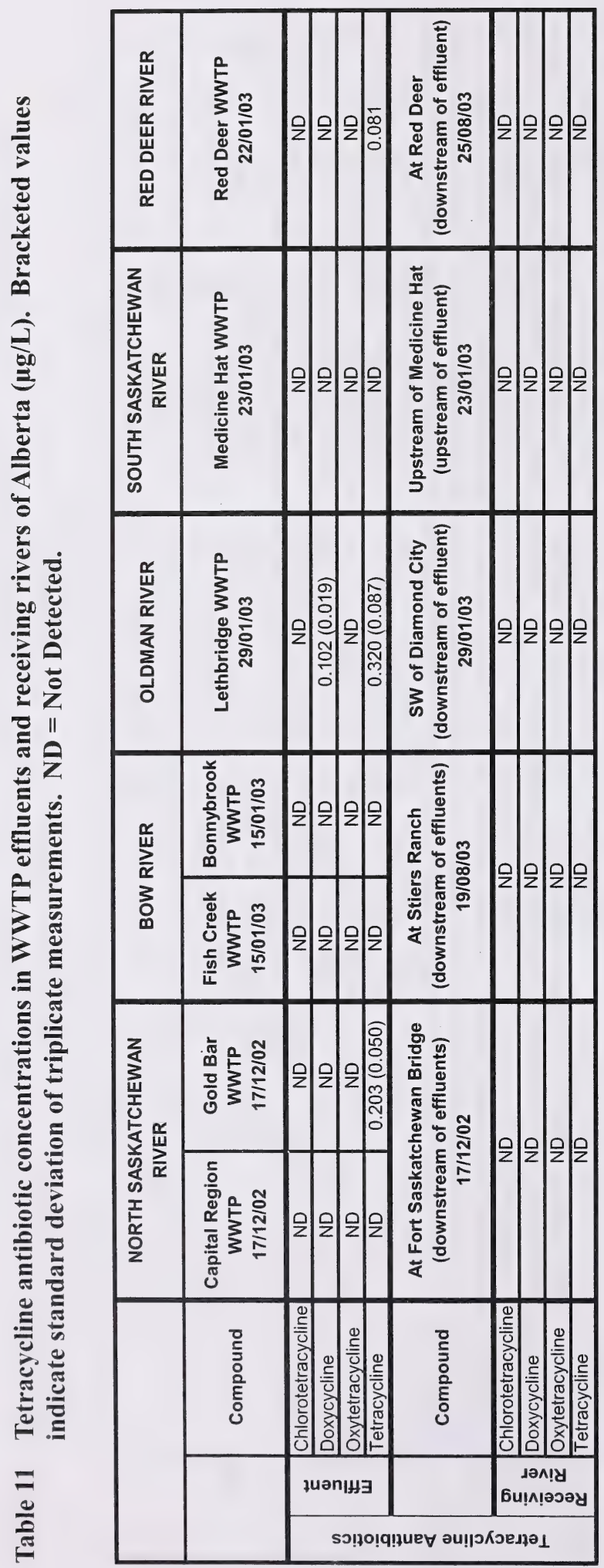




\begin{tabular}{|c|c|c|c|c|c|c|c|c|c|c|c|c|c|c|c|c|c|c|c|c|c|c|c|c|c|c|c|c|c|c|c|c|}
\hline \multirow{2}{*}{ 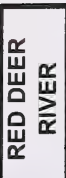 } & \multirow{2}{*}{ 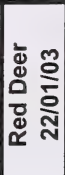 } & 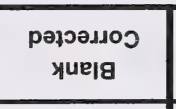 & \multicolumn{2}{|c|}{ 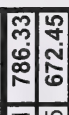 } & 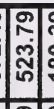 & 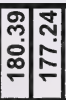 & \multicolumn{2}{|c|}{ लొ } & : & 怘 & & 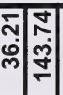 & 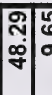 & \multicolumn{2}{|c|}{ ज़: } & 일 & 2 & \multicolumn{2}{|c|}{ 之只 } & 只 & \multicolumn{2}{|c|}{ लू: } & 일웅 & in & \multicolumn{2}{|c|}{ 일 } & 을 & & \multicolumn{2}{|c|}{ 只 } \\
\hline & & 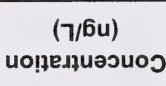 & \begin{tabular}{|}
$\bar{n}$ \\
స్ \\
$\infty$
\end{tabular} & 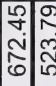 & 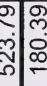 & : & $\mid$ & a & ố & $\mid \begin{array}{l} \\
\infty \\
1 \\
\text { ले }\end{array}$ & $\begin{array}{l}\bar{T} \\
\dot{\gamma} \\
\end{array}$ & $\mid$ & 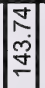 & 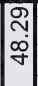 & \begin{tabular}{|l} 
\\
6 \\
6
\end{tabular} & 을 & 일 & $\vec{\nabla}$ & 을 & 只 & 일 & \begin{tabular}{|l|} 
लू \\
के
\end{tabular} & 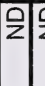 & 일 & \begin{tabular}{|l|l} 
के \\
तi
\end{tabular} & $\overline{2} \overline{2}$ & $\bar{z}$ & z & & & & \\
\hline
\end{tabular}

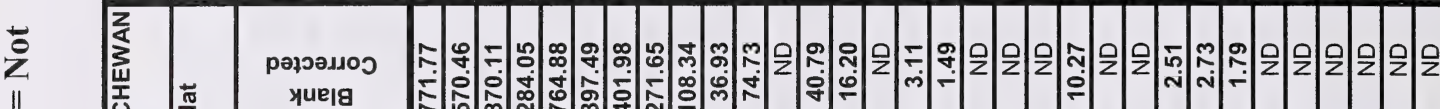

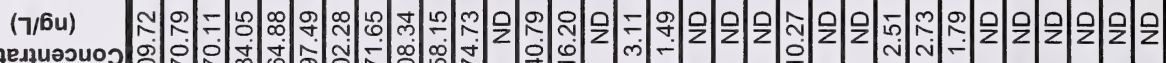

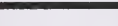

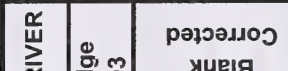

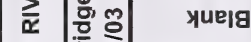

ร

를

z

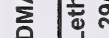

อุ (า/6u)

иo!łeдquэsuos

\begin{tabular}{|c|c|c|c|c|c|c|c|c|c|c|c|c|c|c|c|c|c|c|c|c|c|c|c|c|c|c|c|}
\hline 웅 § & $\begin{array}{c}\text { рәфэ्әноО } \\
\text { प्रие।g }\end{array}$ & 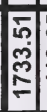 & 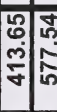 & \begin{tabular}{c|c}
$\frac{\pi}{\pi}$ \\
\end{tabular} & 疍 & \begin{tabular}{l|l} 
फू \\
ते \\
गे
\end{tabular} & ?ִ & 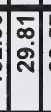 & 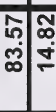 & : & 只 & 只 & 文只 & 을 & & 只只 & : & 논 & & बें & 只 & 只 & 足 & 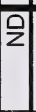 & 全 & & \\
\hline 릉ํํ & uo!̣ed & 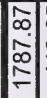 & 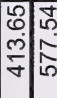 & 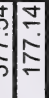 & : & 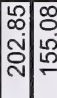 & 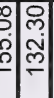 & 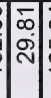 & 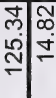 & \begin{tabular}{l|l} 
\\
jo
\end{tabular} & 일 & 을 & 를 & 을 & 2) & 을 & רి & 인단 & 잉 & \begin{tabular}{l|l} 
g. \\
m.
\end{tabular} & 울 & 을 & Q & 只 & 豆 & 吾 & 익 \\
\hline
\end{tabular}

3

인

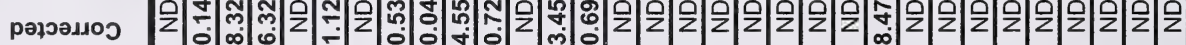

yиeіg

응

드

in

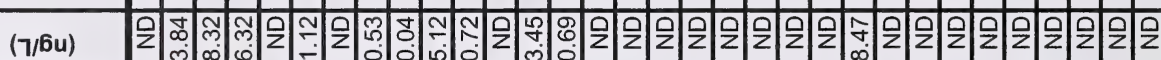

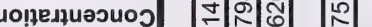

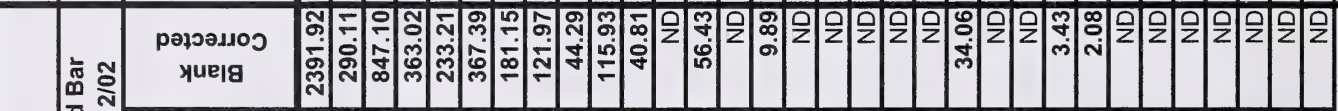

뜬

$(7 / 6 u)$

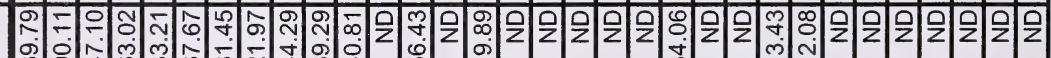

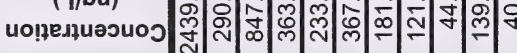

를

西

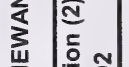

荘 응 ำ

рอรวัวน०ว

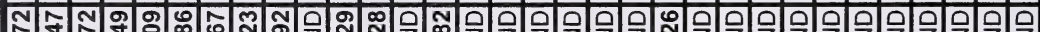

yuelg

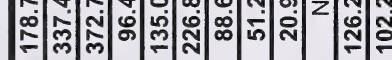

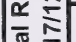

쥰 $(7 / 6 \mathrm{u})$

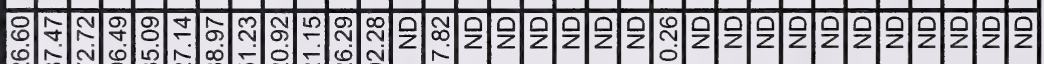

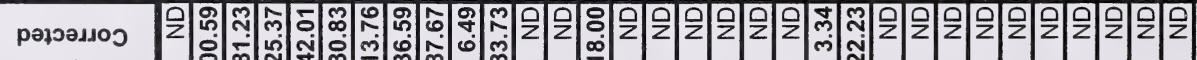
yueı

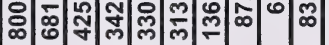

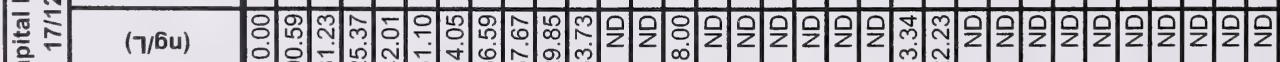




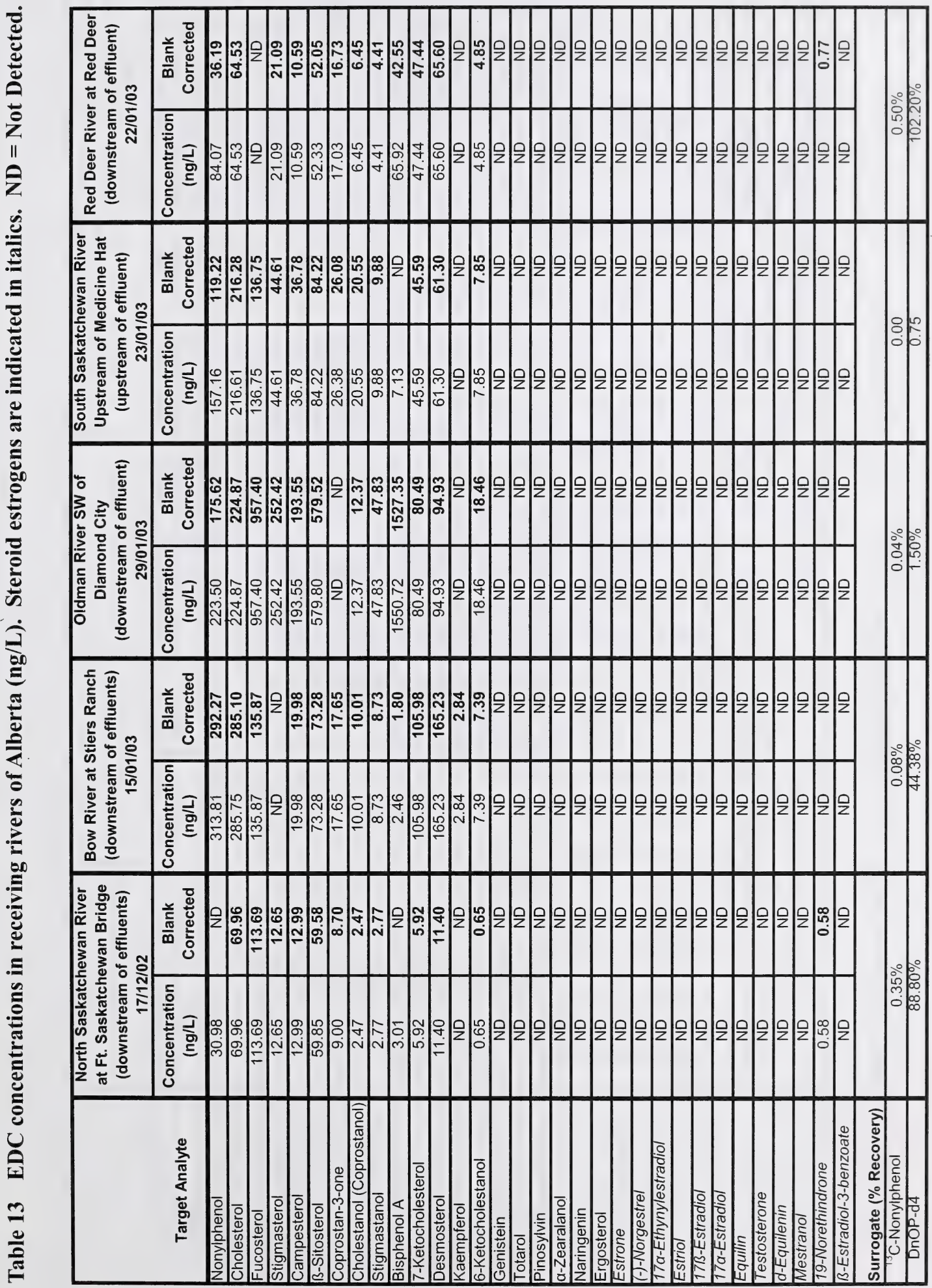




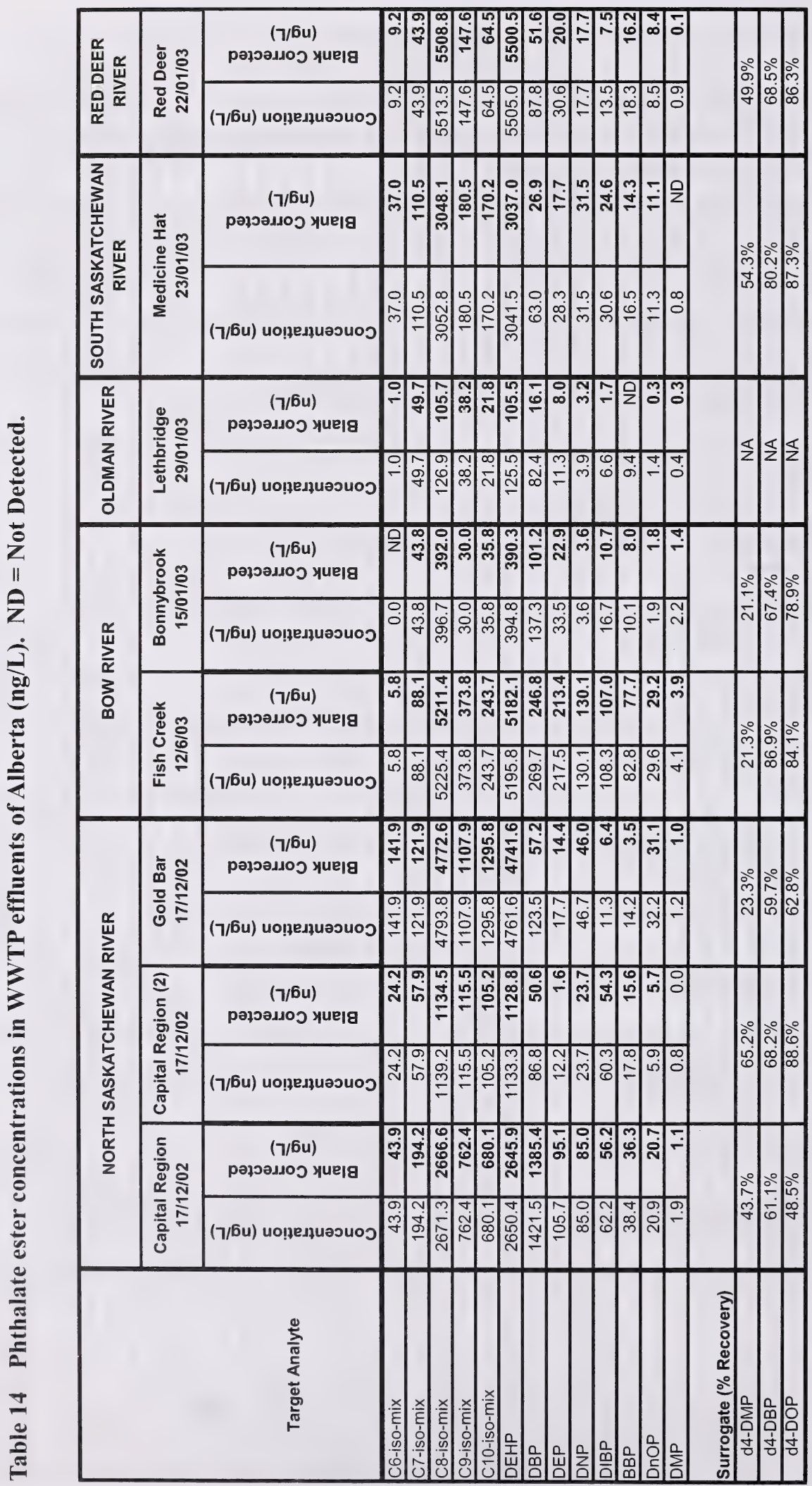




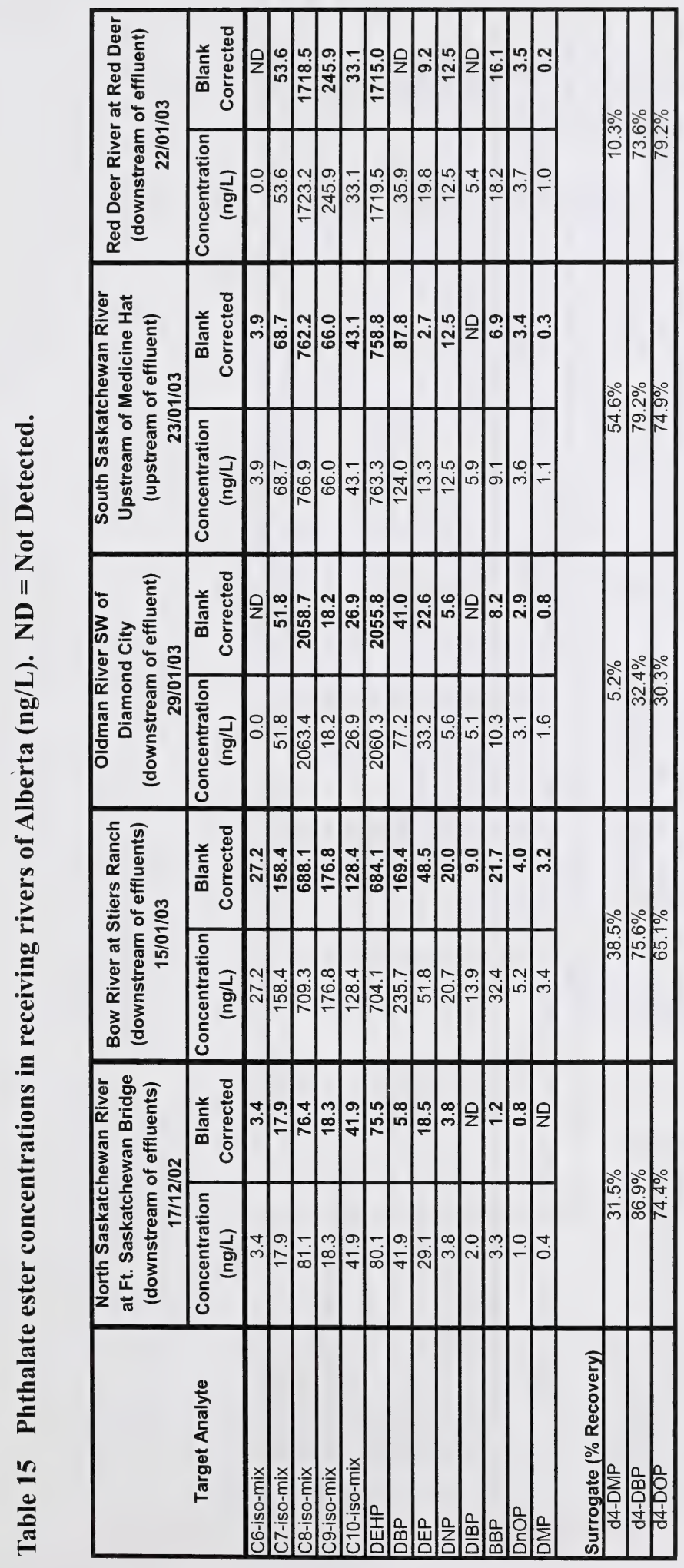




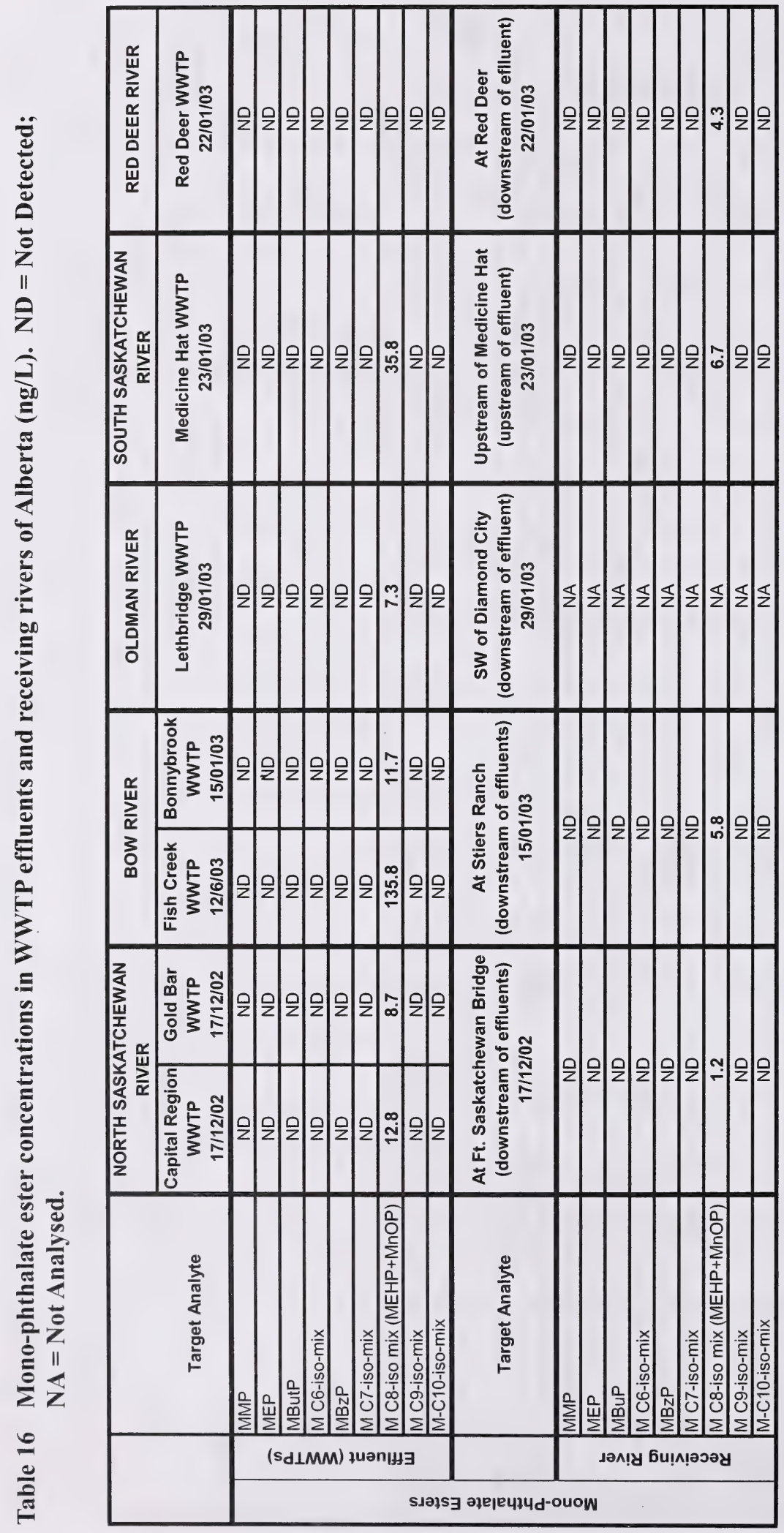




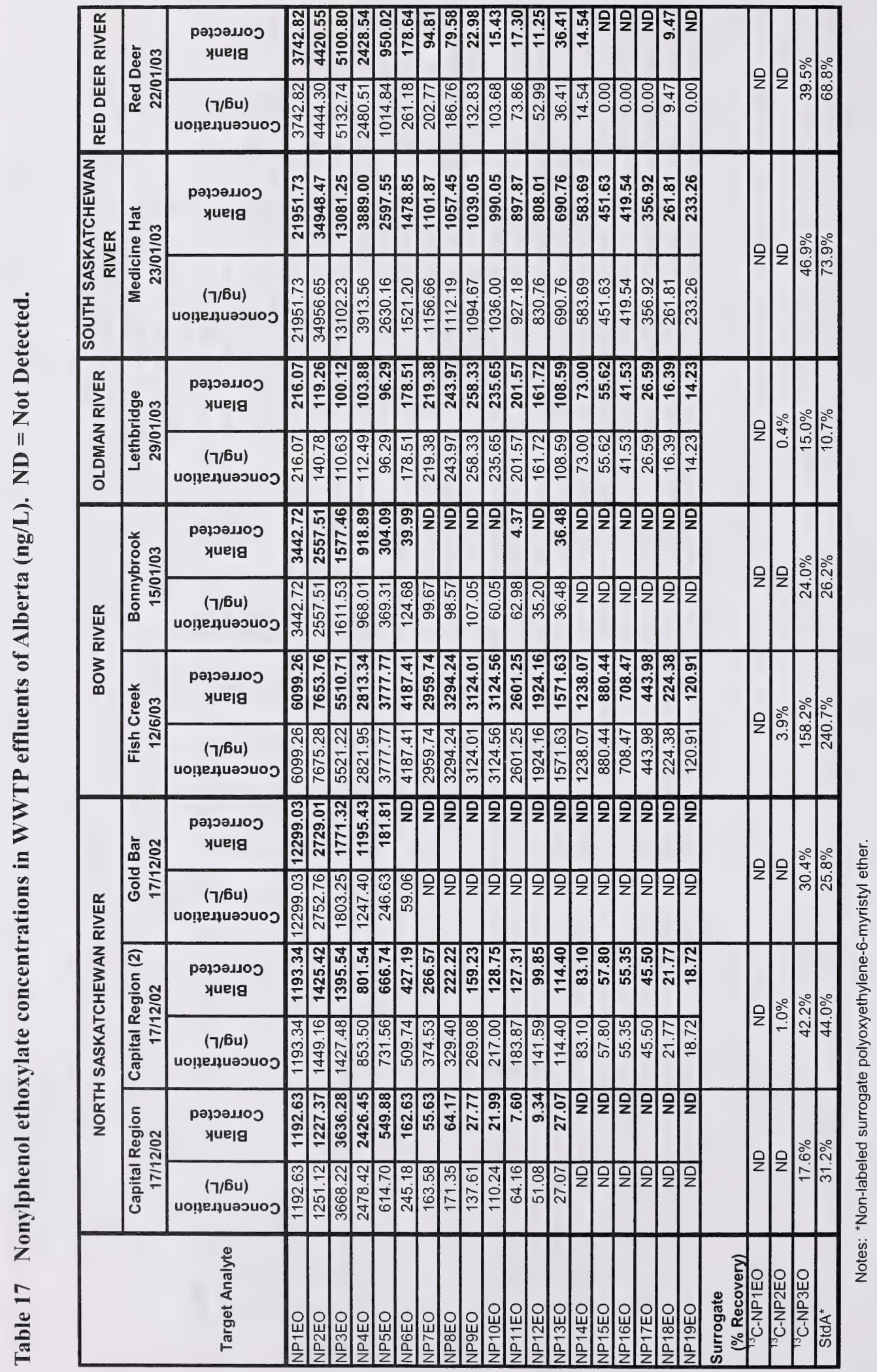




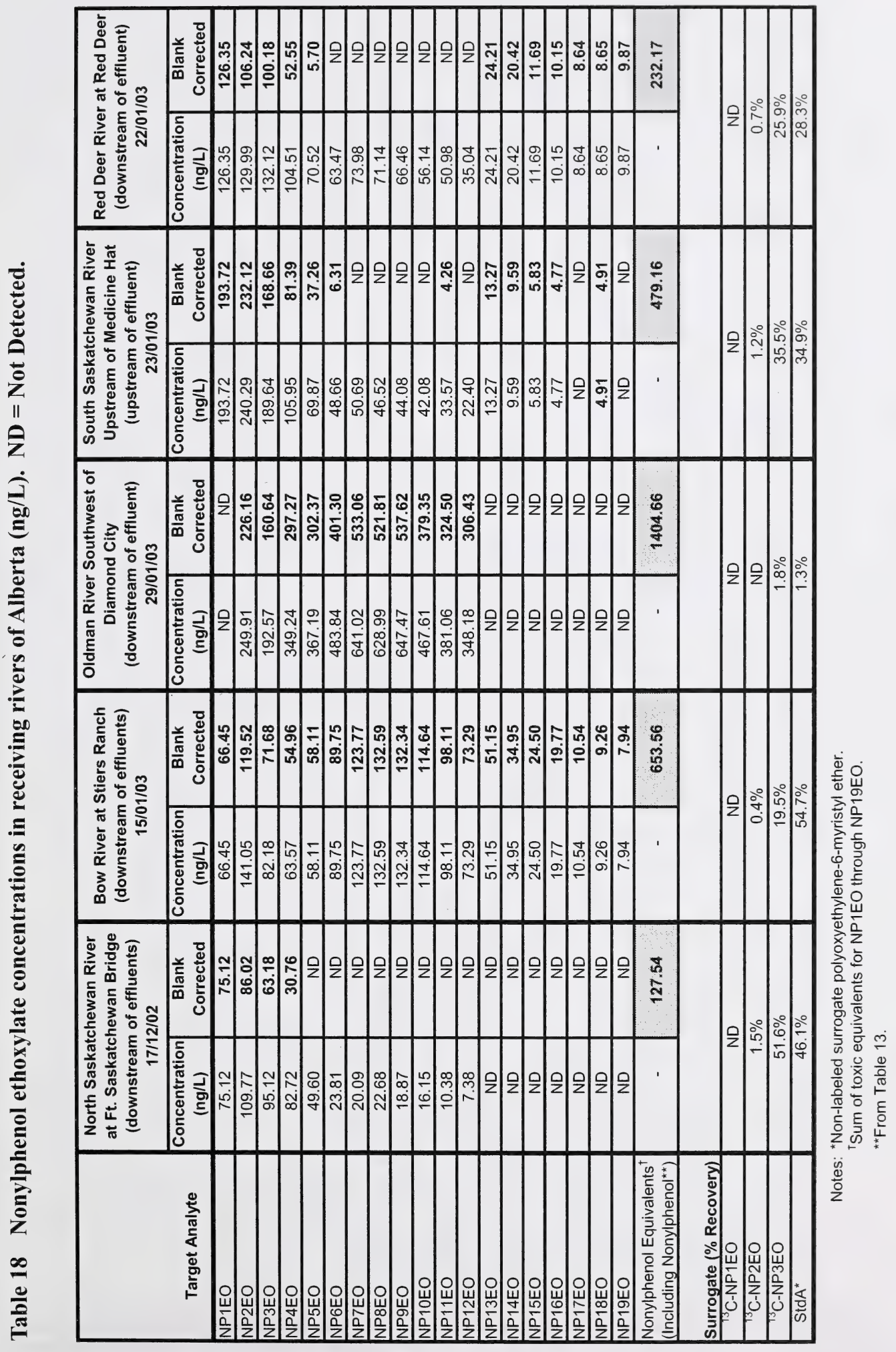




\subsection{FIGURES}


口NSR-Capital Region STP Final Effl.

口NSR-Goldbar STP Final Effl.

口Bow R.-Fish Creek WWTP

口Bow R.-Bonnybrook WWTP

口OMR-Lethbridge WWTP

口SSR-Medicine Hat WWTP

口RDR-Red Deer WWTP
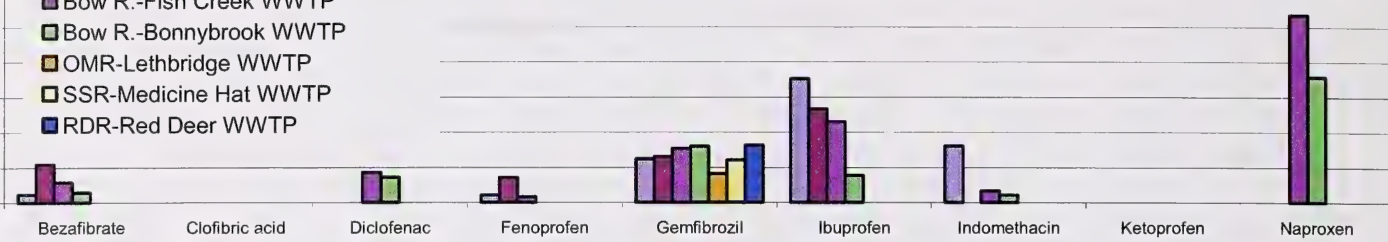

Neutral Drugs

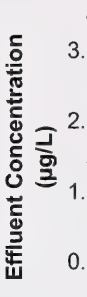

$$
4
$$

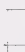
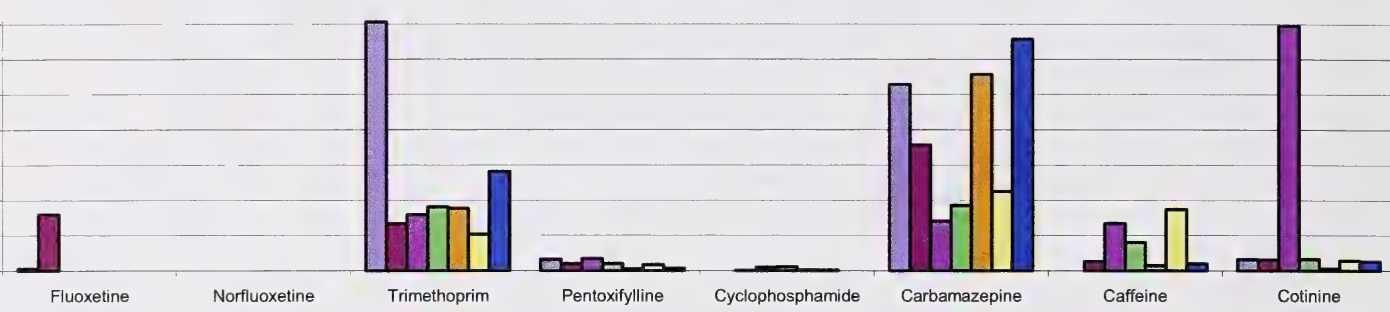

Quinolone Antibiotics

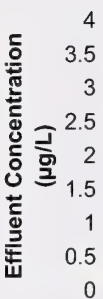

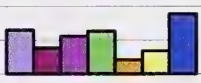

Ciprofloxacin
Enrofloxacin

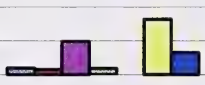

Norfloxacin

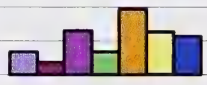

Ofloxacin
Oxolinic acid

Pipemidic acid

Sulfonamide Antibiotics

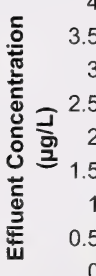<smiles>C1CCCCC1</smiles>

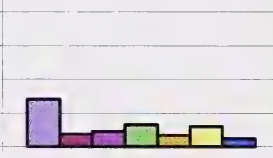

Sulfapyridine

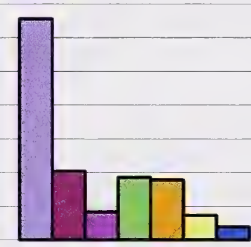

Sulfamethoxazole

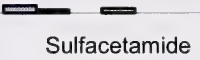

Tetracycline Antibiotics

Figure 1 Pharmaceutical concentrations in WWTP effluents of Alberta. 
घNSR@ Ft. Sask Bridge

口Bow River (D/S) at Stiers Ranch

口Old Man River SW of Diamond City

$\square$ South Sask River upstream Med. Hat

口Red Deer River D/S

Bezafibrate Clofibric acid

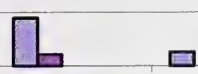

Fenoprofen Gemfibrozil

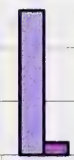

Ibuprofen $\square$

Indomethacin Ketoprofen

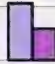

Naproxen

Neutral Drugs
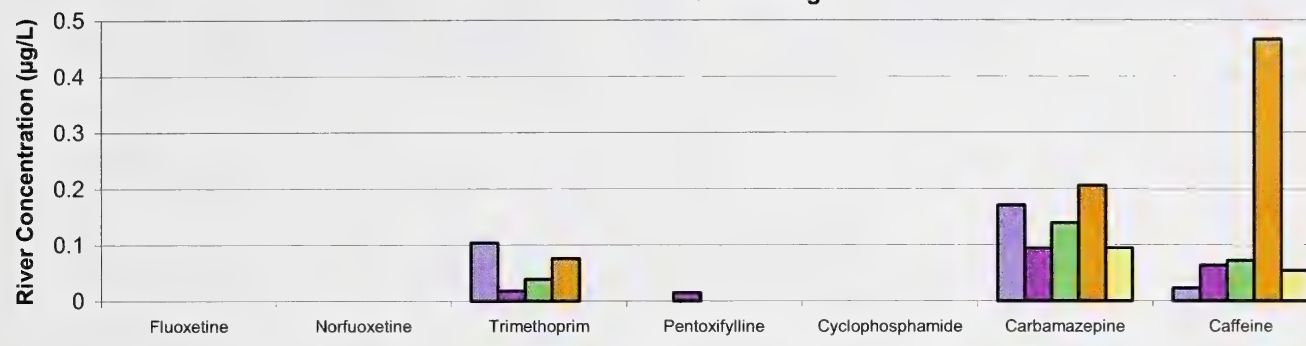

Carbamazepine

Caffeine

Cotinine

Quinolone Antibiotics

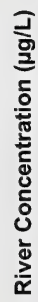
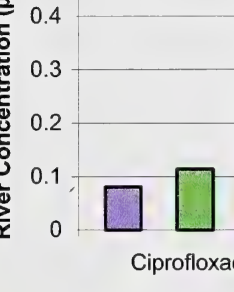

Ciprofloxacin

Enrofloxacin

Norfloxacin

Ofloxacin

Oxolinic acid

Pipemidic acid

Sulfonamide Antibiotics

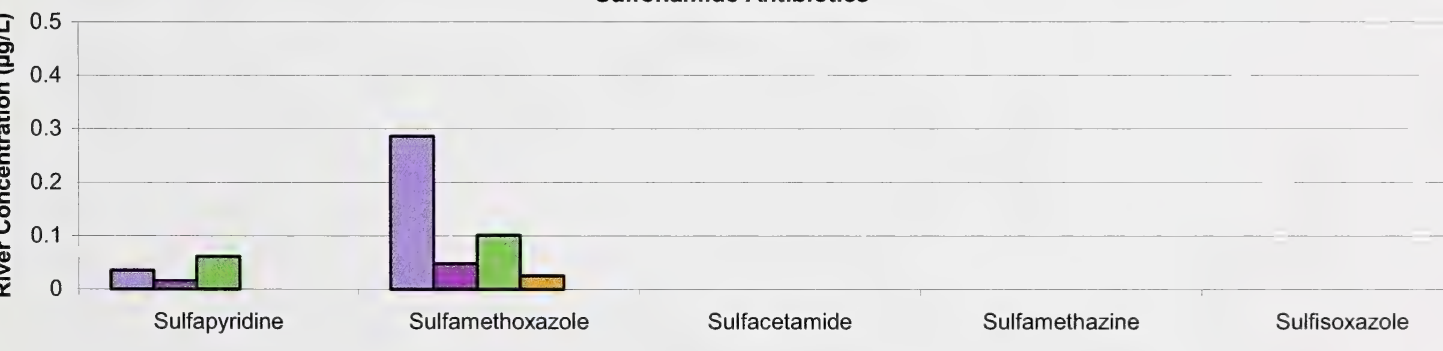

Tetracycline Antibiotics

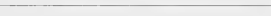

No Detections

Chlorotetracycline

Doxycycline

Oxytetracycline

Tetracycline

Figure 2 Pharmaceutical concentrations in receiving rivers of Alberta.

A Preliminary Survey of Pharmaceuticals and Endocrine Disrupting Compounds in Treated Municipal 
EDCs

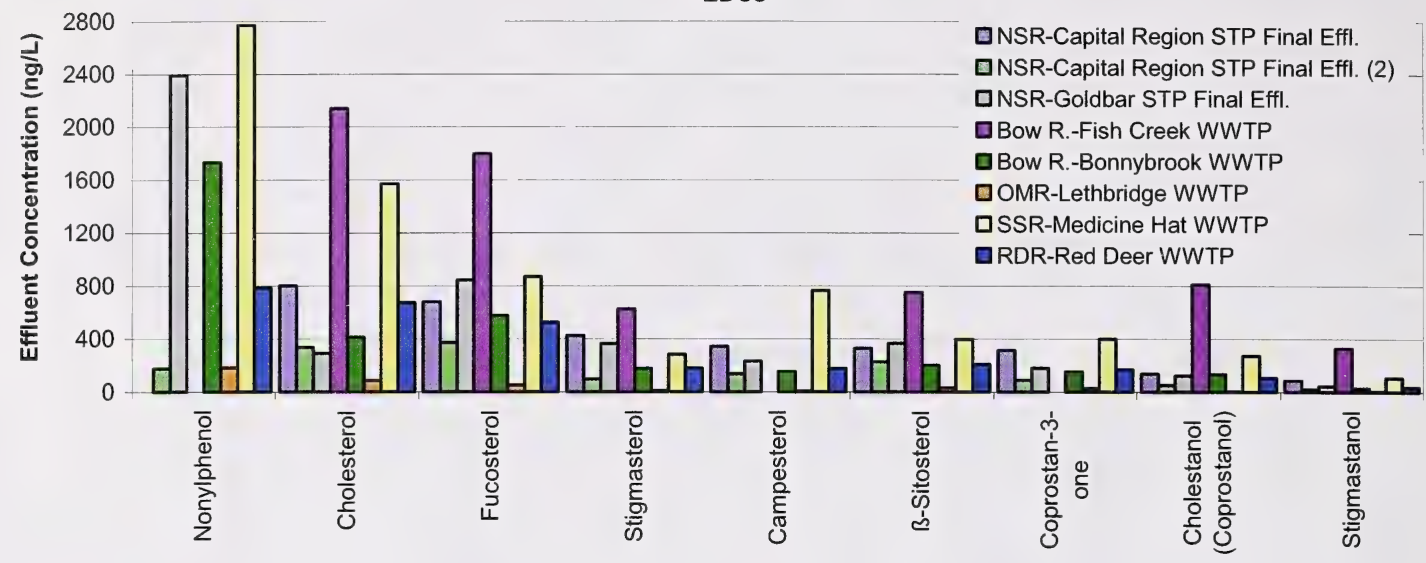

EDCs (continued)

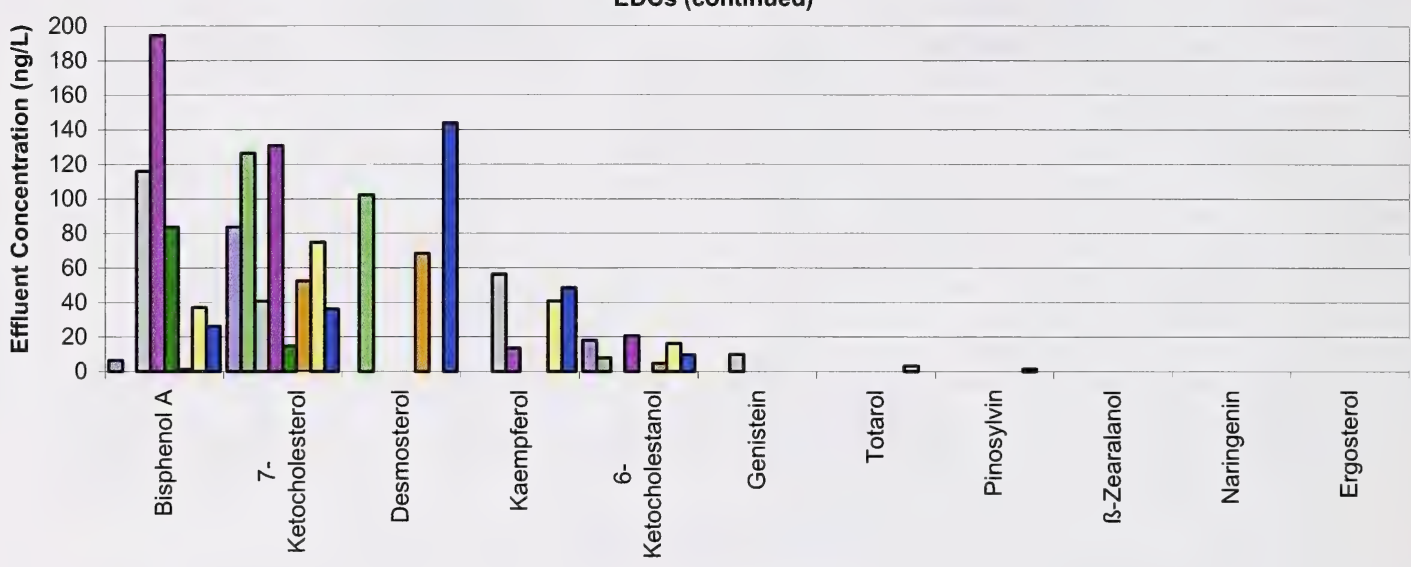

EDCs - Steroid Estrogens

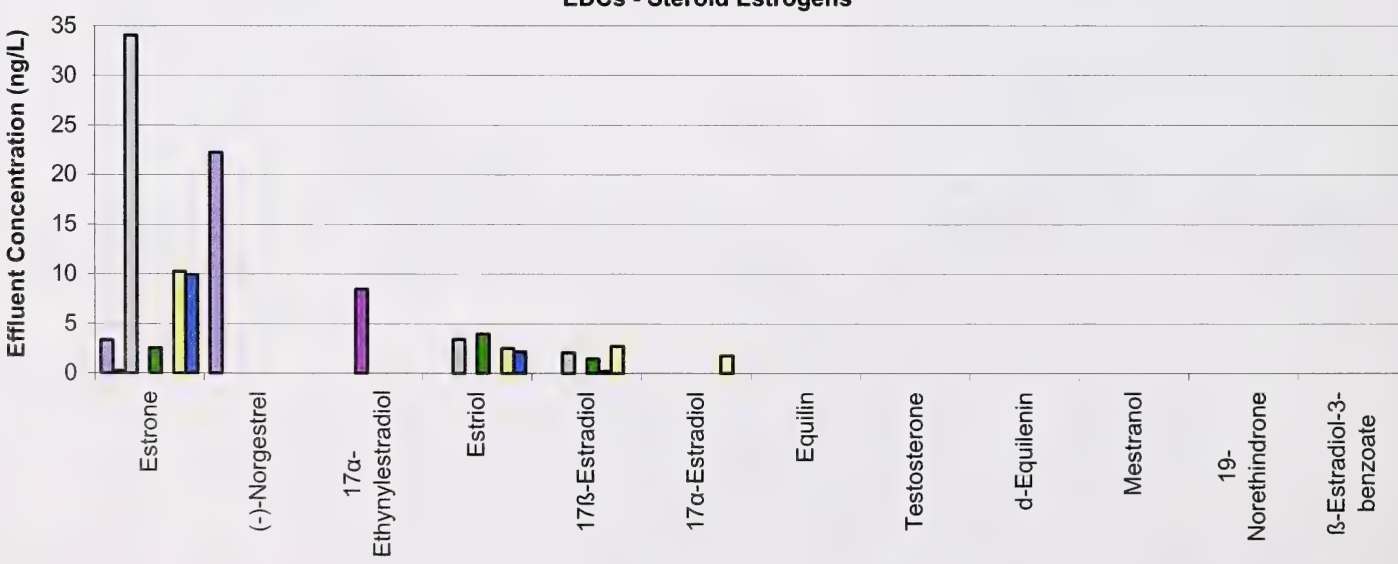

Figure 3 EDC concentrations in WWTP effluents of Alberta (recovery corrected data).

Note scale differences on y-axes.

A Preliminary Survey of Pharmaceuticals and Endocrine Disrupting Compounds in Treated Municipal 

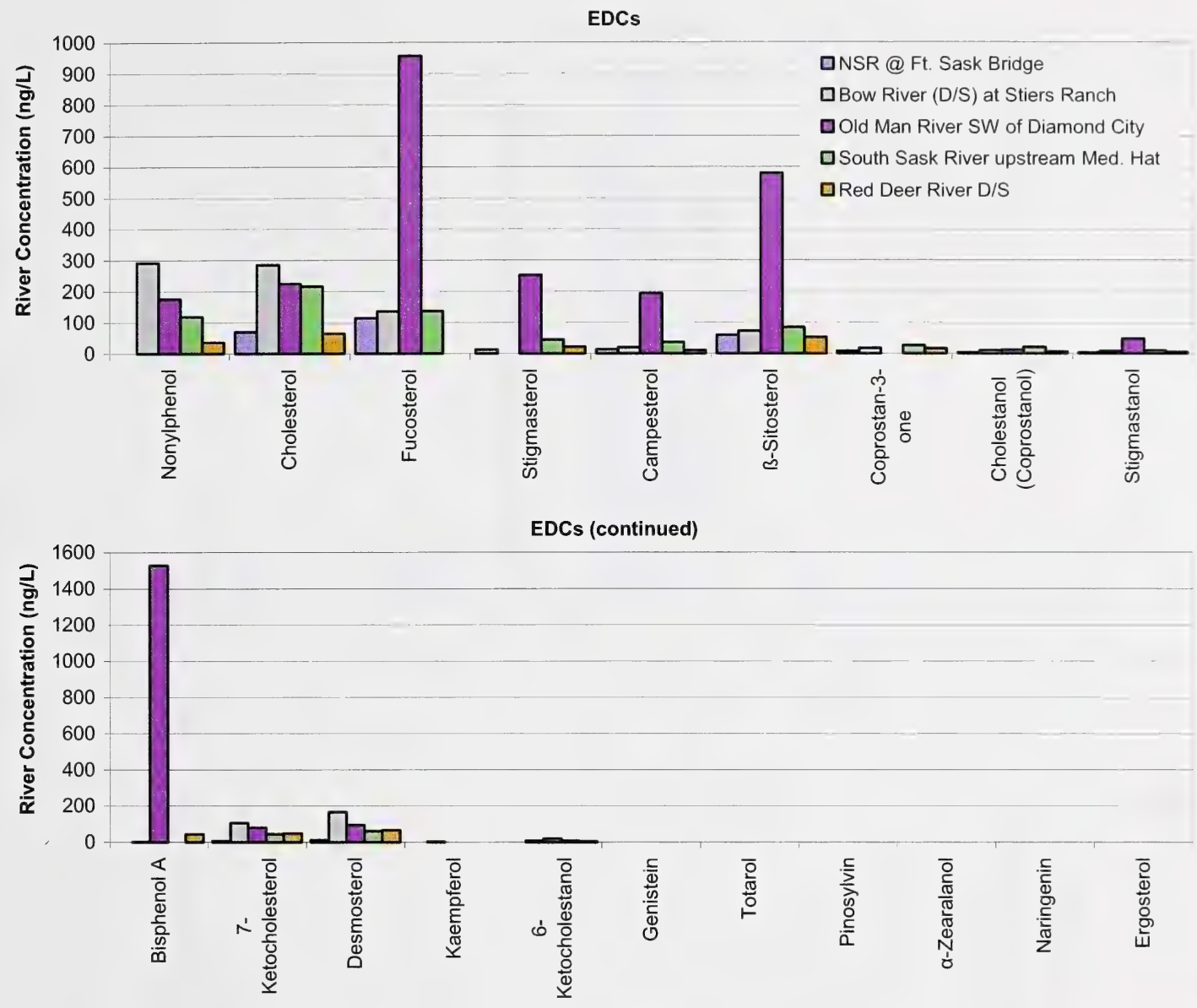

EDCs - Steroid Estrogens

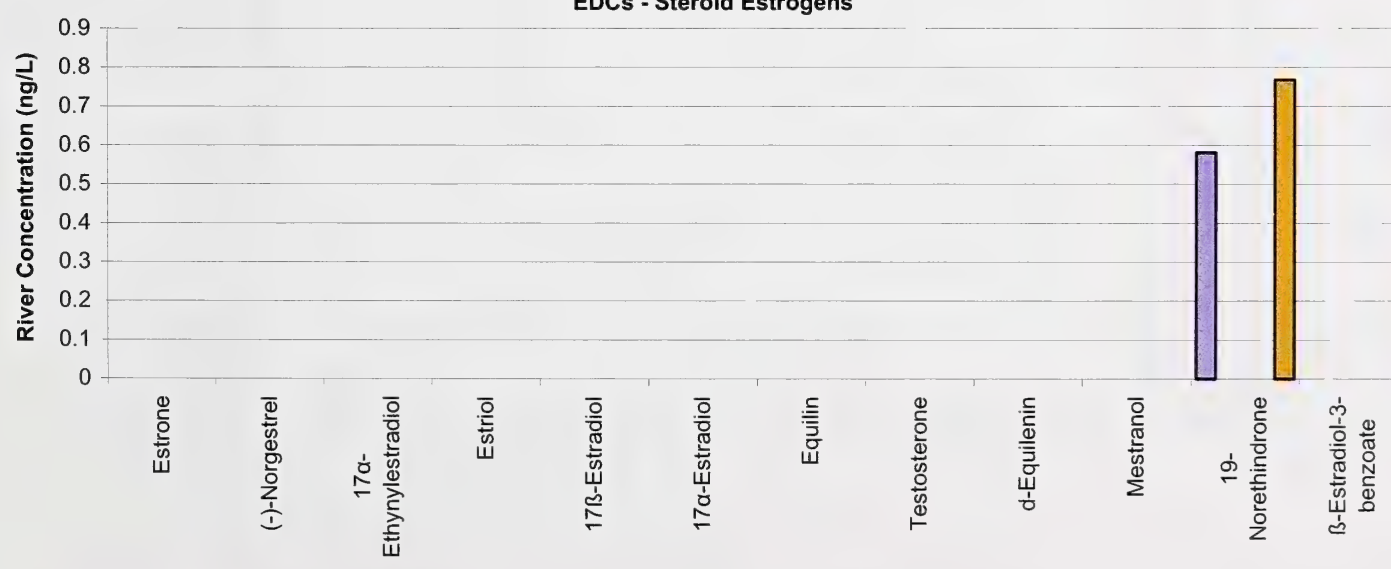

Figure 4 EDC concentrations in receiving rivers of Alberta (recovery corrected data).

Note scale differences on y-axes. 


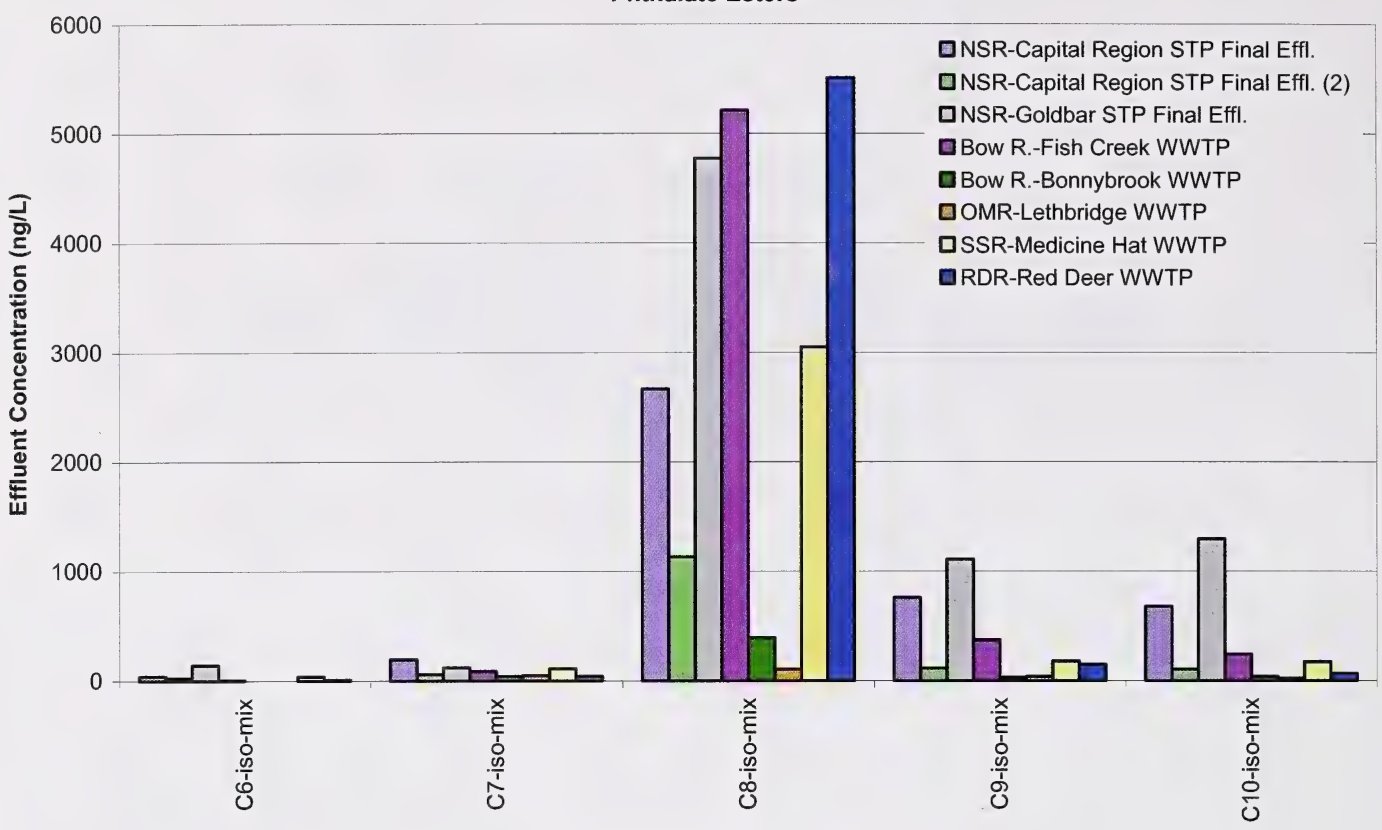

Phthalate Esters (continued)

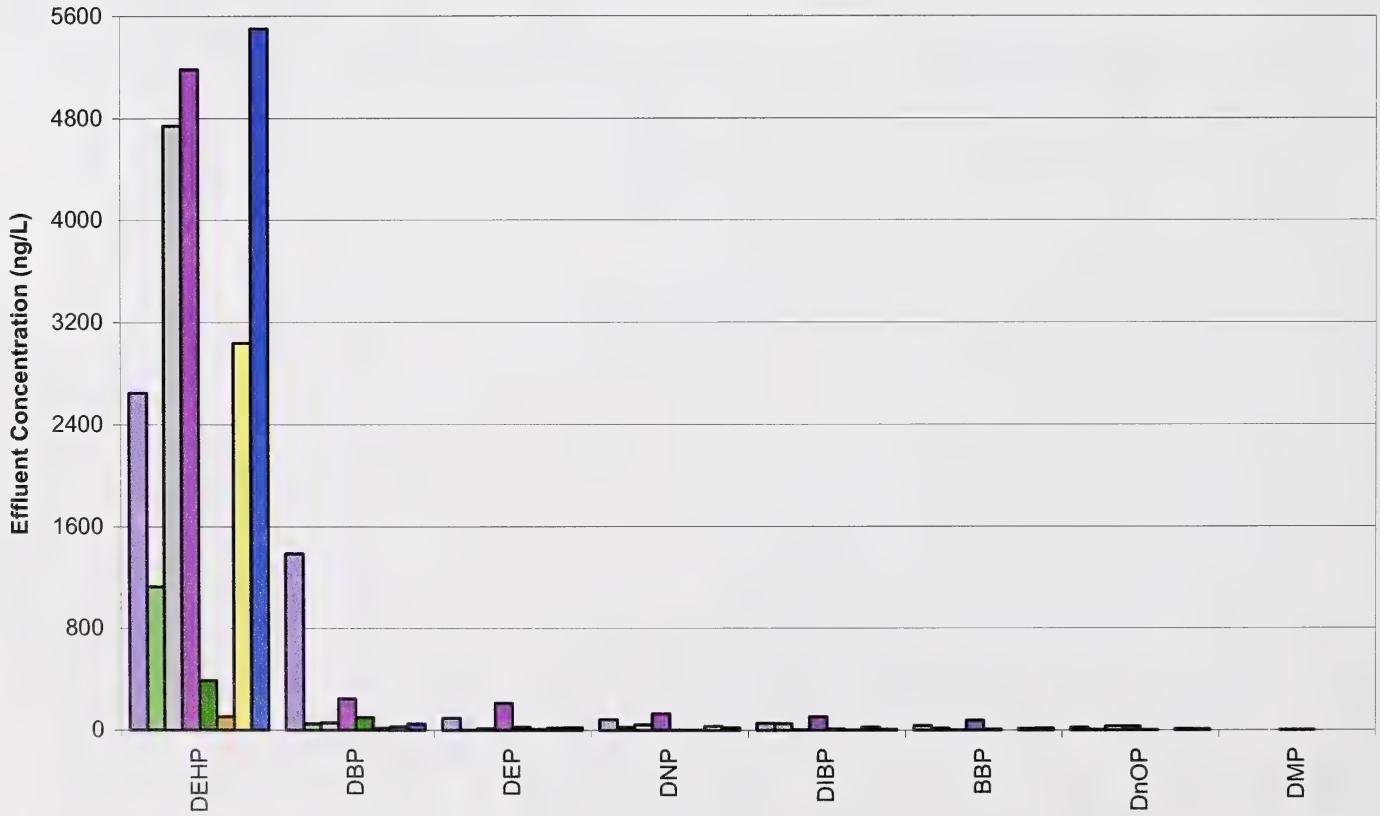

Figure 5 Phthalate ester concentrations in WWTP effluents of Alberta (recovery corrected data). Note scale differences on y-axes. 

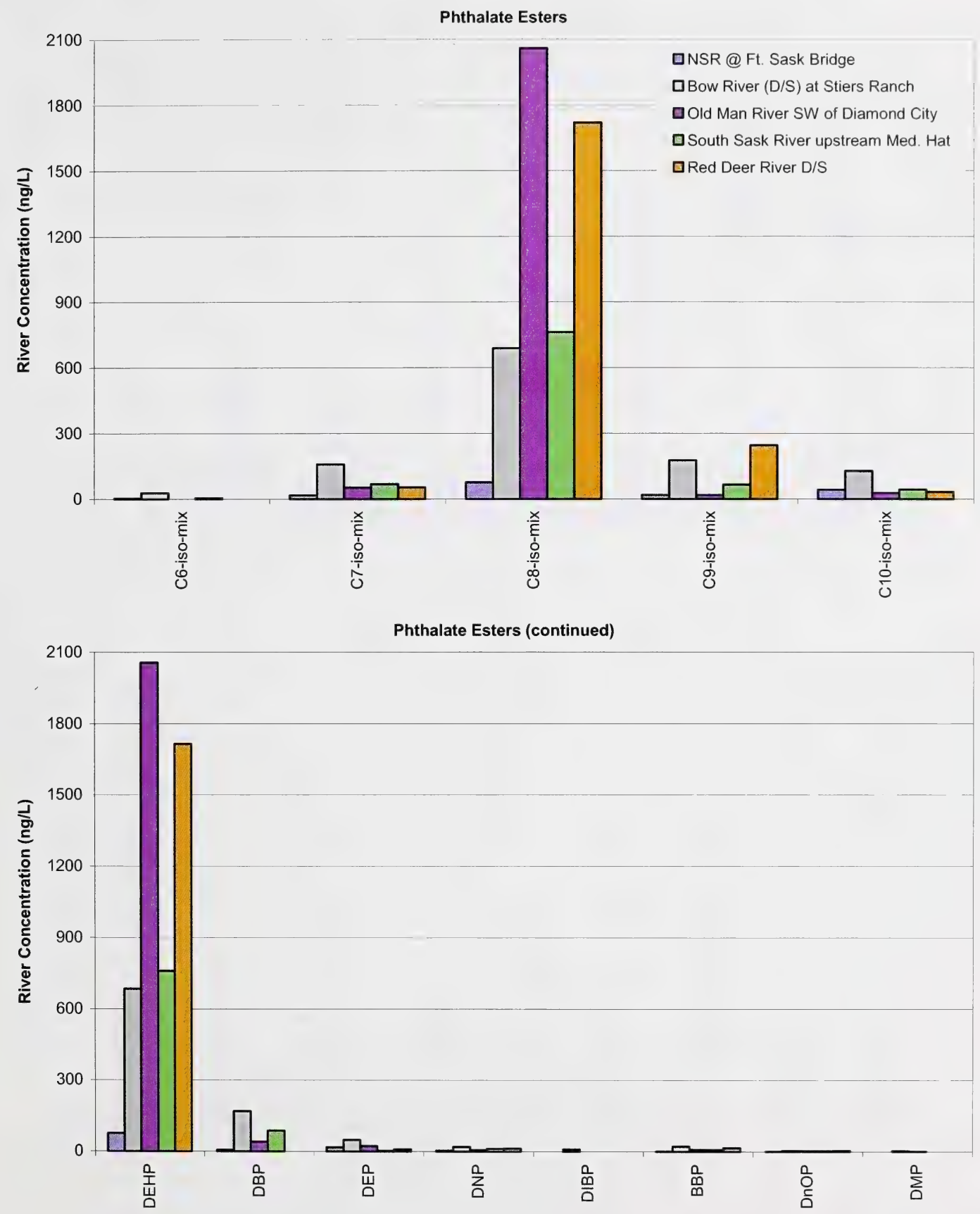

Figure 6 Phthalate ester concentrations in receiving rivers of Alberta (recovery corrected data). 

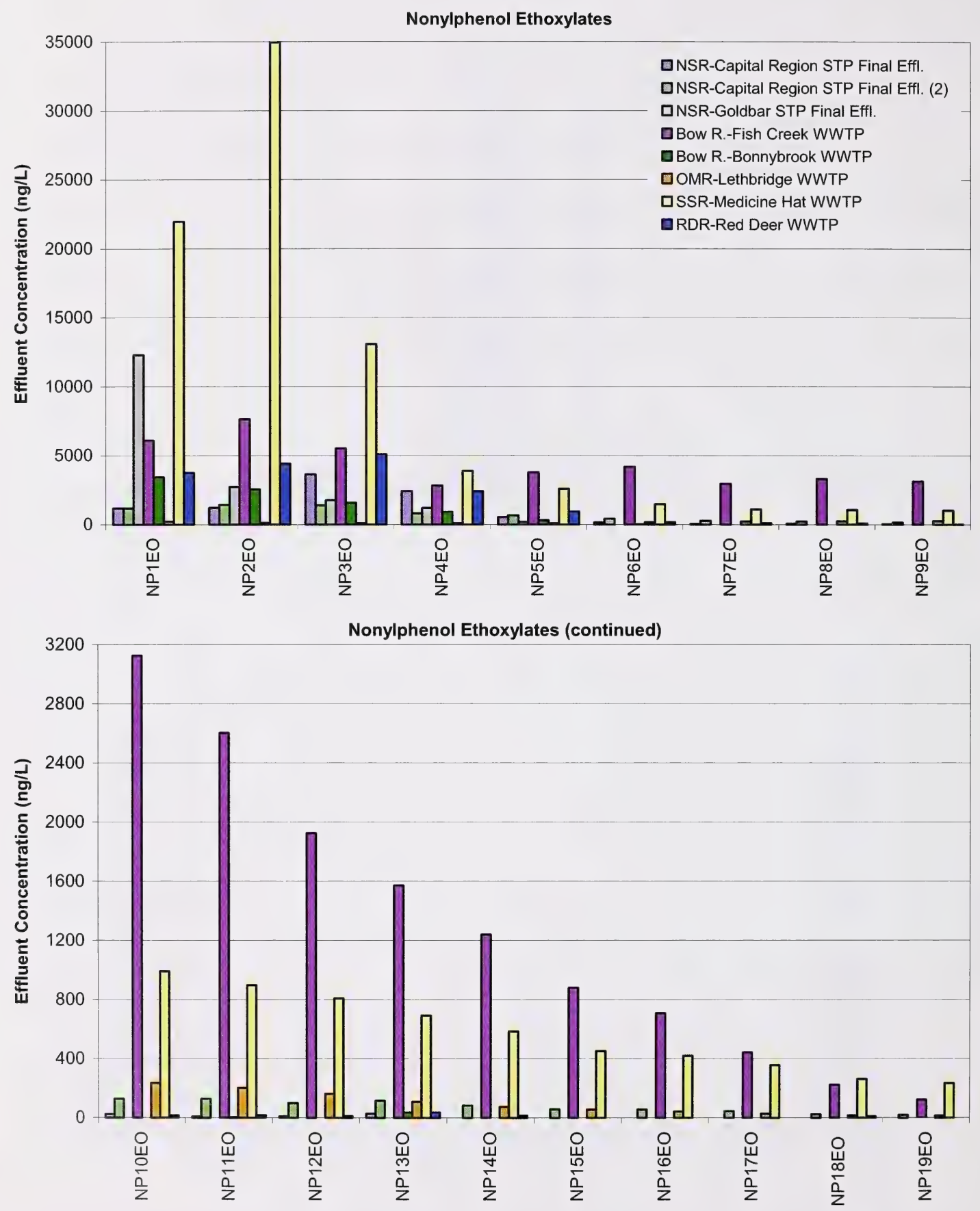

Figure 7 Nonylphenol ethoxylate concentrations in WWTP effluents of Alberta (recovery corrected data). Note scale differences on y-axes. 


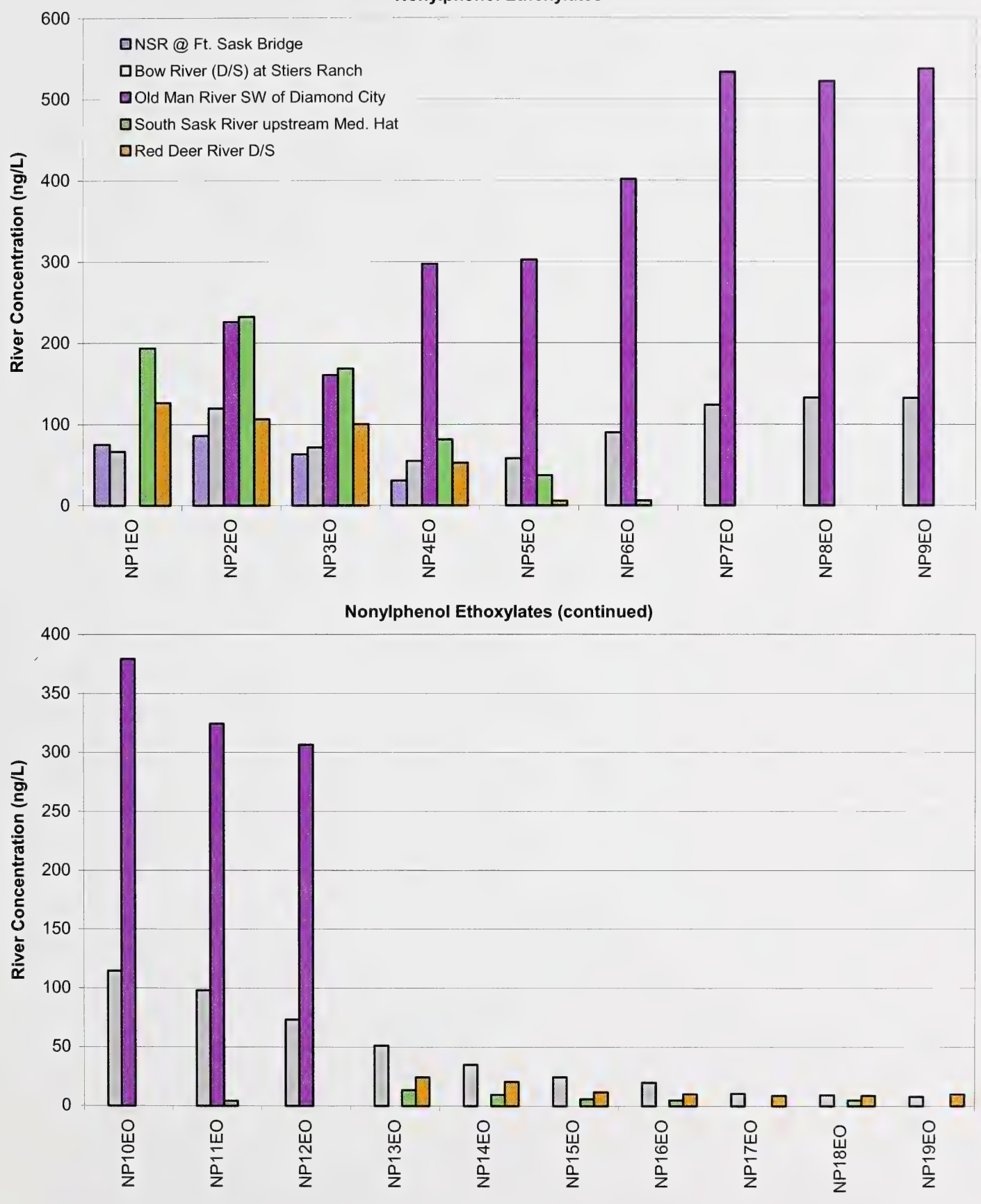

Figure 8 Nonylphenol ethoxylate concentrations in receiving rivers of Alberta (recovery corrected data). Note scale difference on y-axes. 


\subsection{APPENDICES}

A Preliminary Survey of Pharmaceuticals and Endocrine Disrupting Compounds in Treated Municipal 


\section{Appendix I Median recoveries of spiked surrogates from samples of WWTP effluent and}

receiving river water collected in Alberta.

\begin{tabular}{|c|c|c|c|c|c|c|c|}
\hline \multicolumn{8}{|c|}{ Wastewater Treatment Plant Effluents } \\
\hline \multicolumn{2}{|c|}{ EDCs } & \multicolumn{2}{|c|}{ Phthalate Esters } & \multicolumn{2}{|c|}{ Phthalate Monoesters } & \multicolumn{2}{|c|}{ Nonylphenol Ethyoxylates } \\
\hline Surrogate & $\begin{array}{l}\text { Median \% } \\
\text { Recovery }\end{array}$ & Surrogate & $\begin{array}{c}\text { Median \% } \\
\text { Recovery }\end{array}$ & Surrogate & $\begin{array}{c}\text { Median \% } \\
\text { Recovery }\end{array}$ & Surrogate & $\begin{array}{l}\text { Median \% } \\
\text { Recovery }\end{array}$ \\
\hline${ }^{13} \mathrm{C}$-Nonylphenol & 0.37 & d-4 DMP & 43.70 & NA & $\mathrm{NA}$ & ${ }^{13} \mathrm{C}$-NP1EO & $\mathrm{ND}$ \\
\hline \multirow[t]{3}{*}{ DnOP-d4 } & 61.25 & d-4 DBP & 68.20 & NA & $\overline{\mathrm{NA}}$ & ${ }^{13} \mathrm{C}-\mathrm{NP} 2 \mathrm{EO}$ & ND \\
\hline & & $d-4$ DOP & 84.10 & NA & NA & ${ }^{13} \mathrm{C}-\mathrm{NP} 3 \mathrm{EO}$ & 34.95 \\
\hline & & & & & & StdA & 37.60 \\
\hline \multicolumn{8}{|c|}{ Receiving Rivers } \\
\hline \multicolumn{2}{|c|}{ EDCs } & \multicolumn{2}{|c|}{ Phthalate Esters } & \multicolumn{2}{|c|}{ Phthalate Monoesters } & \multicolumn{2}{|c|}{ Nonylphenol Ethyoxylates } \\
\hline Surrogate & $\begin{array}{l}\text { Median \% } \\
\text { Recovery }\end{array}$ & Surrogate & $\begin{array}{c}\text { Median \% } \\
\text { Recovery }\end{array}$ & Surrogate & $\begin{array}{l}\text { Median \% } \\
\text { Recovery }\end{array}$ & Surrogate & $\begin{array}{l}\text { Median \% } \\
\text { Recovery }\end{array}$ \\
\hline${ }^{13} \mathrm{C}$-Nonyiphenol & 0.35 & d-4 DMP & 31.50 & $\overline{\mathrm{NA}}$ & $\overline{N A}$ & ${ }^{13} \mathrm{C}-\mathrm{NP} 1 \mathrm{EO}$ & $\overline{N D}$ \\
\hline \multirow[t]{3}{*}{ DnOP-d4 } & 74.60 & $d-4 D B P$ & 75.60 & NA & NA & ${ }^{13} \mathrm{C}-\mathrm{NP} 2 \mathrm{EO}$ & 0.70 \\
\hline & & $d-4$ DOP & 74.40 & NA & NA & ${ }^{13} \mathrm{C}-\mathrm{NP} 3 \mathrm{EO}$ & 25.90 \\
\hline & & & & & & StdA & 34.90 \\
\hline
\end{tabular}

Notes: $N A=$ Samples were not spiked.

ND $=$ Compound not detected.

StdA = polyoxyethylene-6-myristyl ether 


\section{Appendix II EDC concentrations in blank (type 1, laboratory grade) water samples.}

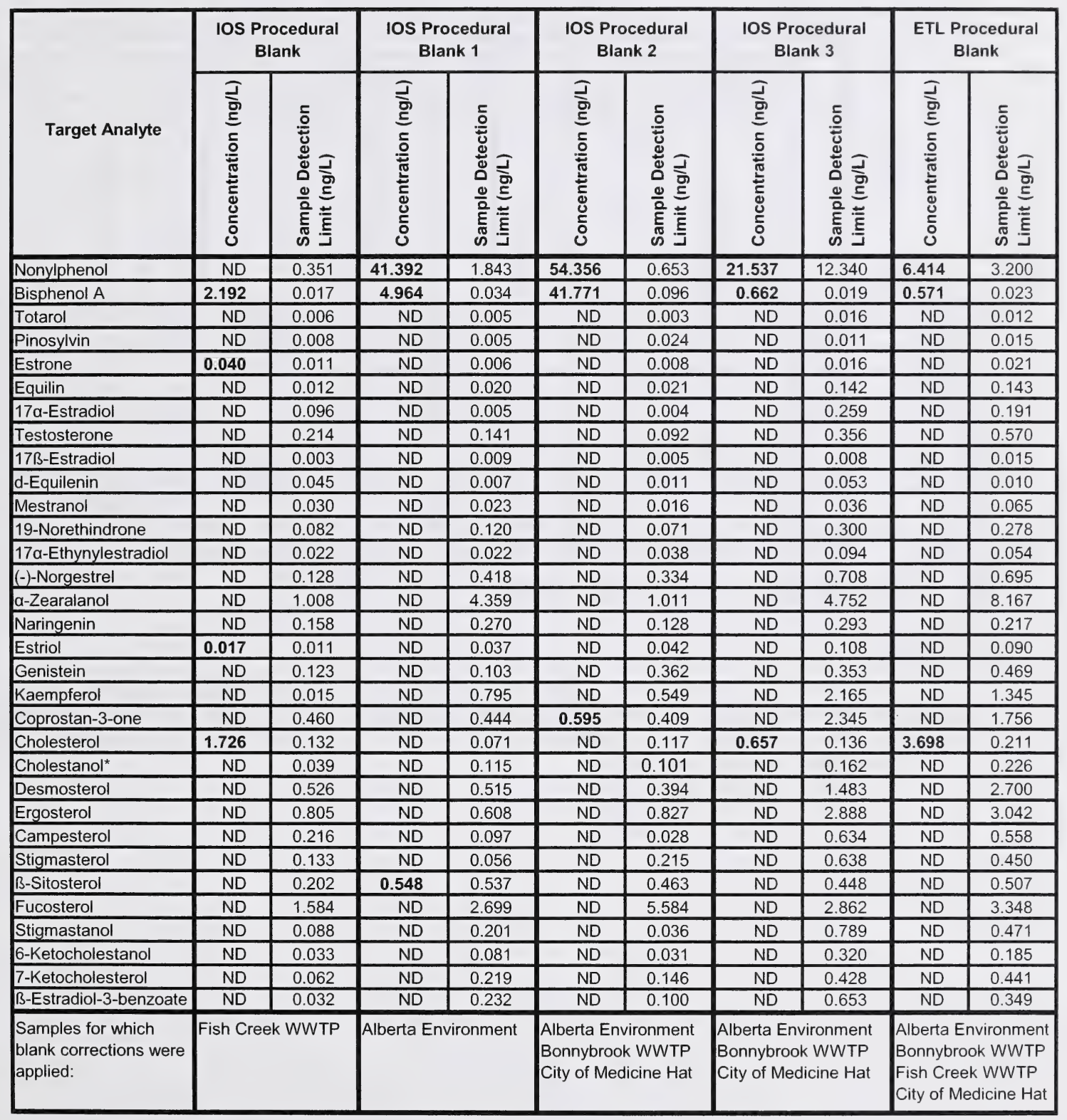

Notes: City of Medicine Hat = Medicine Hat WWTP \& South Saskatchewan River upstream of Medicine Hat. Alberta Environment = All other samples, excluding Fish Creek WWTP, Bonnybrook WWTP, \& Medicine Hat. ND $=$ Compound not detected. IOS = Institute of Ocean Sciences $\mathrm{ETL}=$ Envirotest Laboratories Ltd. *Also known as coprostanol. 


\section{Appendix III Phthalate ester concentrations in blank (type 1, laboratory grade) water samples.}

\begin{tabular}{|c|c|c|c|c|c|c|c|c|c|c|}
\hline \multirow[b]{3}{*}{ Target Analyte } & \multicolumn{4}{|c|}{ Batch 184} & \multicolumn{6}{|c|}{ Batch 191} \\
\hline & \multicolumn{2}{|c|}{$\begin{array}{l}\text { IOS Procedural } \\
\text { Blank } 1\end{array}$} & \multicolumn{2}{|c|}{$\begin{array}{l}\text { IOS Procedural } \\
\text { Blank } 2\end{array}$} & \multicolumn{2}{|c|}{$\begin{array}{l}\text { IOS Procedural } \\
\text { Blank } 1\end{array}$} & \multicolumn{2}{|c|}{$\begin{array}{l}\text { IOS Procedural } \\
\text { Blank } 2\end{array}$} & \multicolumn{2}{|c|}{$\begin{array}{c}\text { ETL Procedural } \\
\text { Blank }\end{array}$} \\
\hline & 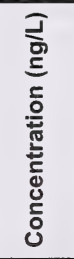 & 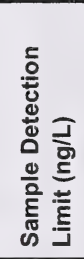 & 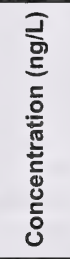 & 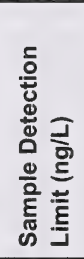 & 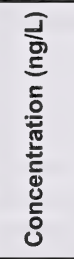 & 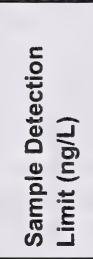 & 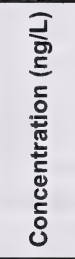 & 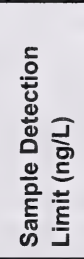 & 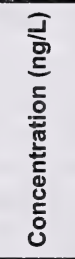 & 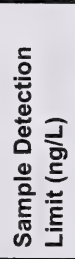 \\
\hline C6-iso-mix & ND & 1.9 & ND & 1.8 & ND & 2.8 & ND & 3.0 & ND & 3.3 \\
\hline C7-iso-mix & ND & 2.4 & ND & 2.1 & ND & 3.5 & ND & 3.8 & ND & 3.6 \\
\hline C8-iso-mix & 4.8 & 0.4 & 4.6 & 0.4 & 26.4 & 0.3 & 15.9 & 0.4 & 11.1 & 3.3 \\
\hline C9-iso-mix & ND & 3.4 & ND & 3.2 & $\mathrm{ND}$ & 3.4 & ND & 3.6 & ND & 2.9 \\
\hline C10-iso-mix & ND & 4.6 & ND & 5.0 & ND & 4.0 & ND & 4.8 & ND & 4.0 \\
\hline DMP & 1.0 & 0.04 & 0.7 & 0.03 & 0.2 & 0.1 & 0.1 & 0.04 & 0.3 & 0.1 \\
\hline DEP & 12.1 & 0.1 & 9.1 & 0.1 & 3.9 & 0.1 & 2.7 & 0.1 & 1.8 & 0.1 \\
\hline DIBP & 6.3 & 0.1 & 5.7 & 0.0 & 5.7 & 0.1 & 4.0 & 0.1 & 6.9 & 0.1 \\
\hline DBP & 38.9 & 0.04 & 33.4 & 0.1 & 79.4 & 0.2 & 53.2 & 0.1 & 24.0 & 0.2 \\
\hline BBP & 2.2 & 0.1 & 2.1 & 0.1 & 13.7 & 0.1 & 7.8 & 0.1 & 2.9 & 0.4 \\
\hline DEHP & 4.8 & 0.2 & 4.3 & 0.2 & 25.9 & 0.2 & 14.2 & 0.2 & 10.8 & 3.2 \\
\hline DnOP & ND & 0.2 & 0.3 & 0.2 & 0.5 & 0.1 & 1.7 & 0.2 & 0.3 & 0.1 \\
\hline DNP & ND & 0.2 & ND & 0.2 & ND & 0.2 & 1.5 & 0.2 & ND & 0.2 \\
\hline \multicolumn{11}{|l|}{$\begin{array}{l}\text { Surrogate } \\
\text { (\% Recovery) }\end{array}$} \\
\hline d-4 DMP & \multicolumn{2}{|c|}{$88.3 \%$} & \multicolumn{2}{|c|}{$89.0 \%$} & \multicolumn{2}{|c|}{$82.6 \%$} & \multicolumn{2}{|c|}{$86.1 \%$} & \multicolumn{2}{|c|}{$\overline{N A}$} \\
\hline d-4 DBP & \multicolumn{2}{|c|}{$102.0 \%$} & \multicolumn{2}{|c|}{$99.4 \%$} & \multicolumn{2}{|c|}{$93.0 \%$} & \multicolumn{2}{|c|}{$94.7 \%$} & \multicolumn{2}{|c|}{ NA } \\
\hline d-4 DOP & \multicolumn{2}{|c|}{$90.3 \%$} & \multicolumn{2}{|c|}{$82.2 \%$} & \multicolumn{2}{|c|}{$78.4 \%$} & \multicolumn{2}{|c|}{$78.3 \%$} & \multicolumn{2}{|c|}{ NA } \\
\hline
\end{tabular}

Notes: $1 O S=$ Institute of Ocean Sciences

$E T L=$ Envirotest Laboratories Ltd

ND $=$ Compound not detected .

NA = Sample was not spiked. 


\section{Appendix IV Phthalate monoester concentrations in blank (type 1, laboratory grade) water samples.}

\begin{tabular}{|c|c|c|c|c|}
\hline \multirow[b]{2}{*}{ Target Analyte } & \multicolumn{2}{|c|}{ IOS Instrument Blank } & \multicolumn{2}{|c|}{$\begin{array}{l}\text { Solvent/Glassware/ } \\
\text { ETL Laboratory Blank }\end{array}$} \\
\hline & 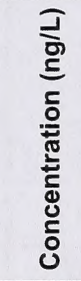 & 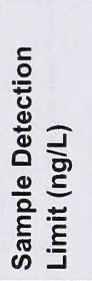 & 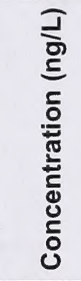 & 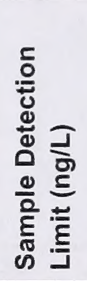 \\
\hline MMP & ND & 5.0 & ND & 5.0 \\
\hline MEP & ND & 5.0 & ND & 5.0 \\
\hline MButP & ND & 6.0 & ND & 6.0 \\
\hline M C6-iso-mix & ND & 12.0 & ND & 12.0 \\
\hline $\mathrm{MBzP}$ & ND & 6.0 & ND & 6.0 \\
\hline M C7-iso-mix & ND & 7.0 & ND & 7.0 \\
\hline M C8-iso mix (MEHP+MnOP) & ND & 4.2 & ND & 4.2 \\
\hline M C9-iso-mix & ND & 6.3 & ND & 6.3 \\
\hline M C10-iso-mix & ND & 7.3 & ND & 7.3 \\
\hline
\end{tabular}

Notes: ND = Compound not detected.

IOS $=$ Institute of Ocean Sciences

$\mathrm{ETL}=$ Envirotest Laboratories Ltd. 


\section{Appendix V Nonylphenol ethoxylate concentrations in blank (type 1, laboratory grade) water samples.}

\begin{tabular}{|c|c|c|c|c|c|c|c|c|c|c|}
\hline \multirow[b]{2}{*}{ 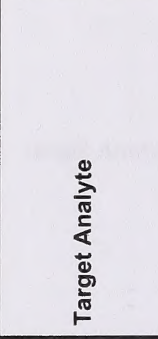 } & \multicolumn{2}{|c|}{$\begin{array}{l}\text { IOS Procedural } \\
\text { Blank }\end{array}$} & \multicolumn{2}{|c|}{$\begin{array}{l}\text { IOS Procedural } \\
\text { Blank1 }\end{array}$} & \multicolumn{2}{|c|}{$\begin{array}{l}\text { IOS Procedural } \\
\text { Blank2 }\end{array}$} & \multicolumn{2}{|c|}{$\begin{array}{l}\text { IOS Procedural } \\
\text { Blank3 }\end{array}$} & \multicolumn{2}{|c|}{$\begin{array}{c}\text { ETL Procedural } \\
\text { Blank }\end{array}$} \\
\hline & 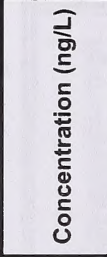 & 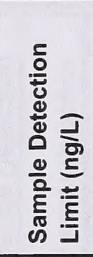 & 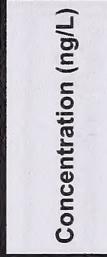 & 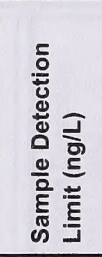 & 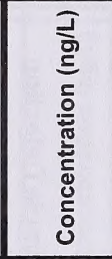 & 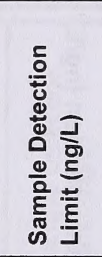 & 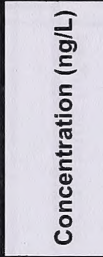 & 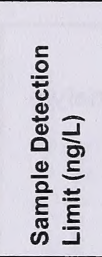 & 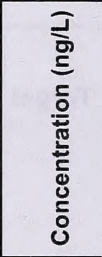 & 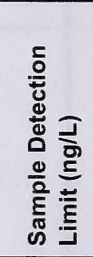 \\
\hline NP1EO & ND & 26.705 & ND & 20.306 & ND & 29.150 & ND & 26.705 & ND & 22.088 \\
\hline NP2EO & 16.353 & 9.072 & 47.493 & 26.418 & ND & 79.094 & 16.353 & 9.072 & 21.523 & 12.671 \\
\hline NP3EO & 7.891 & 3.972 & 29.807 & 13.447 & 34.071 & 15.641 & 7.891 & 3.972 & 10.509 & 4.212 \\
\hline NP4EO & ND & 7.466 & 54.814 & 16.779 & 49.115 & 21.494 & ND & 7.466 & 8.612 & 6.920 \\
\hline NP5EO & ND & 6.945 & 64.423 & 13.468 & 65.223 & 14.387 & ND & 6.945 & ND & 7.341 \\
\hline NP6EO & ND & 9.937 & 80.398 & 42.874 & 84.695 & 19.379 & ND & 9.937 & ND & 12.486 \\
\hline NP7EO & ND & 10.126 & 106.335 & 56.741 & 109.578 & 25.732 & ND & 10.126 & ND & 12.239 \\
\hline NP8EO & ND & 11.195 & 104.882 & 28.592 & 109.477 & 32.490 & ND & 11.195 & ND & 15.154 \\
\hline NP9EO & ND & 8.474 & 108.462 & 22.080 & 111.236 & 20.313 & ND & 8.474 & ND & 8.958 \\
\hline NP10EO & ND & 6.901 & 84.606 & 20.396 & 91.904 & 29.751 & ND & 6.901 & ND & 7.482 \\
\hline NP11EO & ND & 6.194 & 54.504 & 17.884 & 58.616 & 38.982 & ND & 6.194 & ND & 6.980 \\
\hline NP12EO & ND & 4.581 & 37.987 & 32.494 & 45.497 & 24.512 & ND & 4.581 & ND & 4.374 \\
\hline NP13EO & ND & $4: 767$ & ND & 19.227 & ND & 15.975 & ND & 4.767 & ND & 7.576 \\
\hline NP14EO & ND & 6.683 & ND & 5.784 & ND & 18.590 & ND & 6.683 & ND & 7.770 \\
\hline NP15EO & ND & 6.222 & ND & 8.156 & ND & 6.949 & ND & 6.222 & ND & 6.597 \\
\hline NP16EO & ND & 5.336 & ND & 10.887 & ND & 7.992 & ND & 5.336 & ND & 5.707 \\
\hline NP17EO & ND & 5.704 & ND & 7.726 & ND & 11.408 & ND & 5.704 & ND & 6.489 \\
\hline NP18EO & ND & 3.910 & ND & 7.881 & ND & 7.784 & ND & 3.910 & ND & 3.872 \\
\hline NP19EO & ND & 4.224 & ND & 10.586 & ND & 4.746 & ND & 4.224 & ND & 3.180 \\
\hline $\begin{array}{l}\text { Samples for } \\
\text { which blank } \\
\text { corrections } \\
\text { were applied: }\end{array}$ & \multicolumn{2}{|c|}{ Fish Creek WWTP } & \multicolumn{2}{|c|}{ Alberta Environment } & \multicolumn{2}{|c|}{$\begin{array}{l}\text { Alberta Environment } \\
\text { Bonnybrook WWTP } \\
\text { City of Medicine Hat }\end{array}$} & \multicolumn{2}{|c|}{$\begin{array}{l}\text { Alberta Environment } \\
\text { Bonnybrook WWTP } \\
\text { City of Medicine Hat }\end{array}$} & \multicolumn{2}{|c|}{$\begin{array}{l}\text { Alberta Environment } \\
\text { Bonnybrook WWTP } \\
\text { Fish Creek WWTP } \\
\text { City of Medicine Hat }\end{array}$} \\
\hline
\end{tabular}

*Notes: City of Medicine Hat = Medicine Hat WWTP \& South Saskatchewan River upstream of Medicine Hat.

Alberta Environment $=$ All other samples, excluding Fish Creek WWTP, Bonnybrook WWTP, \& Medicine Hat.

ND $=$ Compound not detected.

IOS = Institute of Ocean Sciences

$\mathrm{ETL}=$ Envirotest Laboratories Ltd. 



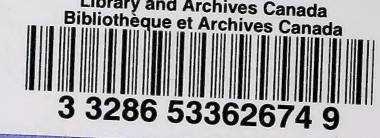

